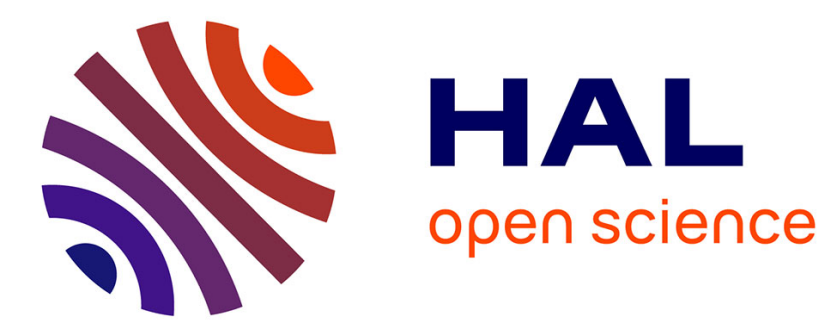

\title{
Gas retention in fine-grained pyroclastic flow materials at high temperatures
}

\author{
Timothy H. Druitt, G. Avard, G. Bruni, P. Lettieri, F. Maez
}

\section{To cite this version:}

Timothy H. Druitt, G. Avard, G. Bruni, P. Lettieri, F. Maez. Gas retention in fine-grained pyroclastic flow materials at high temperatures. Bulletin of Volcanology / Bull Volcanic Eruptions, 2007, 69 (8), pp.881-901. 10.1007/s00445-007-0116-7 . hal-00328920

\section{HAL Id: hal-00328920 \\ https://hal.science/hal-00328920}

Submitted on 5 Dec 2017

HAL is a multi-disciplinary open access archive for the deposit and dissemination of scientific research documents, whether they are published or not. The documents may come from teaching and research institutions in France or abroad, or from public or private research centers.
L'archive ouverte pluridisciplinaire HAL, est destinée au dépôt et à la diffusion de documents scientifiques de niveau recherche, publiés ou non, émanant des établissements d'enseignement et de recherche français ou étrangers, des laboratoires publics ou privés. 


\title{
Gas retention in fine-grained pyroclastic flow materials at high temperatures
}

\author{
T. H. Druitt • G. Avard • G. Bruni • P. Lettieri • F. Maez
}

\begin{abstract}
The ability of a dense pyroclastic flow to maintain high gas pore pressure, and hence low friction, during runout is determined by (1) the strengths and longevities of gas sources, and (2) the ability of the material to retain residual gas once those sources become ineffective. The latter is termed the gas retention capacity. Gas retention capacity in a defluidizing granular material is governed by three timescales: one for the evacuation of bubbles ( $t_{\mathrm{be}}$; brief and not considered in this paper), one for hindered settling from the expanded state $\left(t_{\text {sett }}\right)$, and one for diffusive release of residual pore pressure from the nonexpanded state ( $t_{\text {diff }}$ ). The relative magnitides of $t_{\text {sett }}$ and $t_{\text {diff }}$ depend on bed thickness, $t_{\text {sett }}$ dominating in thin systems and $t_{\text {diff }}$ in thick ones. Three pyroclastic flow materials, two ignimbrites and a block-and-ash flow sample, were studied experimentally to investigate expansion behaviour under gas flow and to determine gas retention times. Effects of particle size were evaluated by using two size cuts $(<4 \mathrm{~mm}$ and $<250 \mu \mathrm{m}$ ) from each sample. Careful drying of the materials was necessary to avoid effects of humidity-related cohesion. Two sets of experiments were carried out: (1) expansion in the non-bubbling regime at $50-200^{\circ} \mathrm{C}$, (2) bed collapse tests from the initially bubbling state at $50-550^{\circ} \mathrm{C}$. Provided that gas channelling was avoided by gentle
\end{abstract}

T. H. Druitt $(\bowtie) \cdot$ G. Avard $\cdot$ F. Maez

Laboratoire Magmas et Volcans,

Université Blaise Pascal CNRS \& IRD,

Clermont-Ferrand, France

e-mail: t.druitt@opgc.univ-bpclermont.fr

G. Bruni $\cdot$ P. Lettieri

Department of Chemical Engineering,

University College London,

London, UK stirring, all the samples exhibited a regime of uniform expansion prior to the onset of bubbling. Fine particle size (in particular high fines content), low particle density and high temperature all favoured smoother fluidization by increasing the maximum expansion possible in the nonbubbling state. An empirical equation describing the uniform expansion of the materials was determined. High temperature also favoured greater gas partitioning into the dense phase of the bubbling bed, as well (in finer-grained samples) as higher voidage in the settled bed. Large values of $t_{\text {sett }}$ and $t_{\text {diff }}$ were favoured by fine particle size. Temperature had less influence, suggesting that experimental results at low temperatures $\left(50-200^{\circ} \mathrm{C}\right)$ can be extrapolated to higher temperatures. Gas retention times provide insight into the ability of pyroclastic flows in expanded $\left(t_{\text {sett }}\right)$ or non-expanded $\left(t_{\text {diff }}\right)$ flow states to retain gas once air ingestion or gas production have become ineffective. Finer-grained pyroclastic flows are expected to retain gas longer, and hence to have higher apparent 'mobilities', than coarser-grained ones of comparable volume, as has been observed on Montserrat.

Keywords Pyroclastic flows · Fluidization - Sedimentation · Hindered settling $\cdot$ Montserrat

\section{Introduction}

Pyroclastic flows are a common hazard around volcanoes, yet their physical behaviour is not well understood. They are hard to observe, and quantitative measurements of their dynamics and material properties are rare. Of particular interest is how pyroclastic flows are able to travel large distances on slopes much lower than the normal angle of rest of granular materials; i.e., why they are so 'mobile'. In 
this paper we focus on dense pyroclastic flows with an essentially free surface that travel in a manner analogous to debris flows. Friction reduction in such flows is commonly attributed to fluidization caused by excess gas pore pressure, supplemented by interparticle collisions and buoyancy effects from the fine-grained matrix (Sparks 1976; Wilson 1980; Druitt 1998; Freundt and Bursik 2001).

The degree of friction reduction varies with flow type and volume. The fronts of block-and-ash flows come to rest on slopes ranging from $\sim 30^{\circ}$ for very small collapses to a few degrees for large ones (Davies et al. 1978; Boudon et al. 1993; Yamamoto et al. 1993; Cole et al. 2002). Most pumice flows of even small volume are highly mobile, flowing on slopes of a few degrees or less before ceasing motion (Wilson and Head 1981; Hoblitt 1986; Calder et al. 2000; Cole et al. 2002). Pumice flows form by fountain collapse and many are initiated as expanded, turbulent currents (e.g., Rowley et al. 1985). As particles settle, the lower, and progressively denser, levels of the current decouple and become confined topographically. With increasing distance the current becomes separated into two layers: a dense pumice flow and a dilute ash cloud. The high mobility of pumice flows shows that the particulate load is supported very effectively, not only during the proximal turbulent phase, but throughout most of the flow path. Realistic modelling of a pumice flow at Mt. St. Helens using an inviscid flow law is consistent with negligible friction (Levine and Kieffer 1991). A similarly high degree of particle support is needed to explain the motion of surgederived pyroclastic flows on Montserrat. These formed by rapid settling from pyroclastic surge clouds, forming smallvolume, high-concentration flows of ash that swept down drainages with gradients of only a few degrees (Druitt et al. 2002).

A key question is how high gas pressures are maintained in the dense gas-pyroclast mixture throughout the duration of transit: typically several minutes in the case of small flows (Hoblitt 1986; Cole et al. 2002). Two factors are involved: (1) the strengths and longevities of any gas sources and (2) the ability of the flow to retain residual gas once those sources become ineffective. This paper addresses the second factor, which we term the gas retention capacity.

We carried out experiments in 1-D fluidization rigs to evaluate the gas retention capacities of pyroclastic flow materials. The work was the first stage in an ongoing programme to generate and study flows of fluidized ash on a laboratory scale (Girolami et al. 2006). In a first set of experiments we studied the 1-D expansion behaviour of the materials when fluidized; in a second set we observed how the expanded materials re-sedimented under gravity when the gas flux was turned off. The samples came from two ignimbrites and a block-and-ash flow deposit, two different sieve cuts of each material being used to explore particle size and density effects. Operating temperatures from 50 to $550^{\circ} \mathrm{C}$ were used to explore thermal effects. High temperature affects particle-gas mixtures by (a) decreasing the density of the gas phase, (b) increasing gas viscosity (doubling between room temperature and $550^{\circ} \mathrm{C}$ ), and (c) modifying particle surface properties and the strengths of interparticle cohesive forces (Yates 1996). We then used a numerical model to illustrate some key processes involved in the defluidization of a gas-particle mixture and to identify the governing timescales. These gas retention times were then determined for the natural samples and the effects of material properties and temperature were evaluated. We begin by reviewing some basic concepts of gas-fluidized systems.

\section{Fluidization and sedimentation in gas-particle systems}

\section{Fluidization concepts}

A granular material is said to be fluidized if the vertical drag force exerted by the gas is equal to the weight of the particles. In a monodisperse (single particle size and density) material this occurs at the minimum fluidization velocity $U_{\mathrm{mf}}$, expressed as the superficial value calculated by dividing the gas volume flux by the surface area of the empty container at the temperature of operation. The superficial gas velocity for a fine powder is given by Darcy's Law:

$U=-\frac{K}{\mu}\left(\frac{\mathrm{d} P}{\mathrm{~d} z}+\rho_{g} g\right)$

where $z$ is height (positive upwards), $\rho_{\mathrm{g}}$ is gas density, $\mu$ is gas viscosity, $P$ is gas pressure, and $K$ is permeability (symbols are defined in the Appendix). Applying this at minimum fluidization gives:

$U_{\mathrm{mf}}=-\frac{K_{\mathrm{mf}}}{\mu}\left(\frac{\mathrm{d} P}{\mathrm{~d} z}+\rho_{\mathrm{g}} g\right)$

The pressure gradient at minimum fluidization is given by

$\frac{\mathrm{d} P}{\mathrm{~d} z}=-g\left[\varepsilon \rho_{g}+(1-\varepsilon) \rho_{s}\right]$

where $\rho_{\mathrm{s}}$ is particle density and $\varepsilon$ is hydrodynamic voidage, so that Eq. 2 becomes

$U_{\mathrm{mf}}=\frac{K_{\mathrm{mf}}}{\mu}(1-\varepsilon)\left(\rho_{s}-\rho_{g}\right) g$

The hydrodynamic voidage is that 'seen' by the gas flow, and excludes any voids within particles. Several parameterisations for $K_{\mathrm{mf}}$ are given in standard texts (e.g., Rhodes 
1998; Fan and Zhu 1998). A material in which $U_{\mathrm{mf}}>U>0$ is said to be aerated and one in which $U \geq U_{\mathrm{mf}}$ is said to be fluidized. The dynamic gas pressure gradient is lithostatic at all levels in a fluidized bed.

Geldart (1973) classified monodisperse powders into four groups, A to D, according to fluidization behaviour. Group C materials (particles small and/or light) are dominated by cohesive forces greater than those exerted on the particles by the flowing gas. Flow is focussed into channels and full bed support is hard to achieve. In the absence of sintering, cohesion in group $\mathrm{C}$ materials is due to adsorbed water, electrostatic forces and/or van der Waals forces. Group A materials (particles of intermediate size or density) expand uniformly over a certain velocity range above $U_{\mathrm{mf}}$ before the onset of bubbling at $U_{\mathrm{mb}}$, the minimum bubbling velocity (e.g. Abrahamsen and Geldart 1980a) (Fig. 1a). In groups B and D (particles coarse and/or dense) bubbles form as soon as $U_{\mathrm{mf}}$ is exceeded, so that $U_{\mathrm{mf}} \approx U_{\mathrm{mb}}$ and no uniform expansion regime exists. A material with a broad regime of uniform expansion is said to have high fluidization quality.

Fluidization properties of pyroclastic flow materials

Pyroclastic flow materials contain particles ranging in size from metres to microns and components ranging from pumice to dense rock fragments; particles of all four Geldart groups are present. Owing to the poor sorting, gas velocity can exceed the terminal fall velocity of the smallest particles before it reaches $U_{\mathrm{mf}}$ of the largest ones, causing
Fig. 1 Schematic a expansion and $\mathbf{b}$ collapse behaviours of the pyroclastic flow materials of this study, with definition of parameters referred to in the text. Experiments of set 1 studied expansion behaviour between $U_{\mathrm{mp}}$ and $U_{\mathrm{mb}}$ at temperatures of $50-200^{\circ} \mathrm{C}$. Experiments of set 2 studied settling behaviour from $U>U_{\mathrm{mb}}$ at $50-550^{\circ} \mathrm{C}$
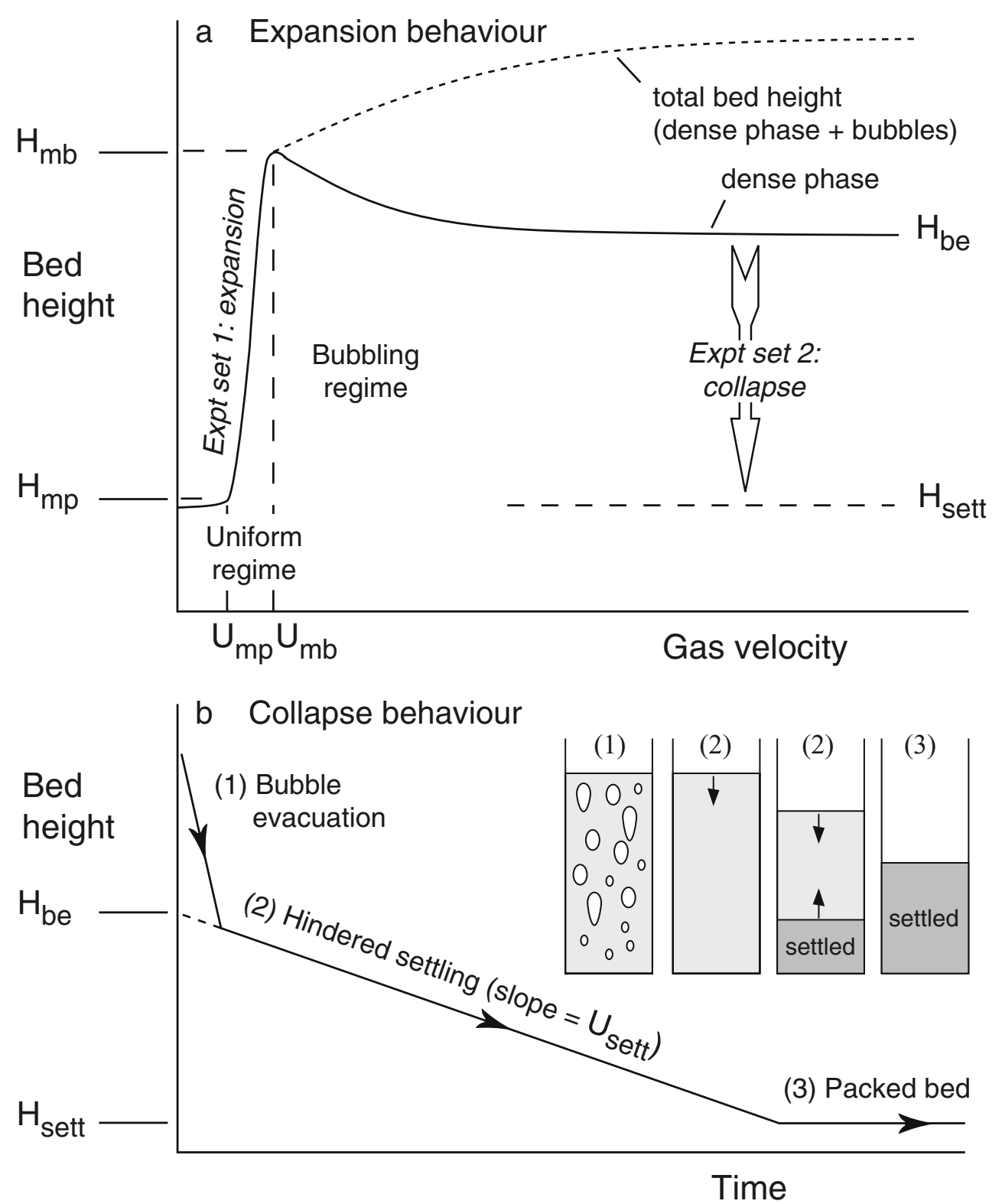
elutriation (Sparks 1976). To emphasise this difference from monodisperse materials, Wilson (1980) replaced $U_{\mathrm{mf}}$ by $U_{\mathrm{mp}}$, the superficial gas velocity corresponding to the maximum pressure drop tolerated by the bed. Another effect is that when $U_{\mathrm{mp}}$ is exceeded, particle size and density segregation sets in and the bed gets richer in coarse/ dense particles at the base and richer in fine/light particles at the top (Wilson 1980, 1984).

Druitt et al. (2004) fluidized fine-grained samples of ignimbrite at temperatures up to $\sim 550^{\circ} \mathrm{C}$. They showed that if gas channelling is suppressed by gentle stirring, then the materials expand in the manner of a group A material (Fig. 1a). The ability of stirring to improve fluidization quality is well known (e.g., Nezzal et al. 1998).

\section{Sedimentation}

Sedimentation behaviour has been studied in collapse tests by first expanding the bed, then turning off the gas flow and letting the powder settle under its own weight (e.g., Abrahamsen and Geldart 1980b; Geldart and Wong 1985; Lettieri et al. 1999; Bruni et al. 2006, 2007). Collapse of a group A material takes place first by rapid bubble evacuation, then by hindered settling and sediment accumulation (Fig. 1b). Collapse of group B powders occurs solely by bubble evacuation. Group $\mathrm{C}$ powders collapse in an exponential manner by densification throughout the bed as gas is forced out through progressively smaller channelways. Druitt et al. (2004) found that sub-4 mm cuts of ignimbrite collapsed like group A powders (Fig. 1b), provided that they had been efficiently pre-dried. Samples that had adsorbed too much atmospheric moisture exhibited group $\mathrm{C}$ behaviour.

It is well known that fluidization and hindered settling are dynamically equivalent (Richardson and Zaki 1954). Consider a 1-D suspension of particles settling at velocity $u_{\mathrm{s}}$. By continuity (and taking the upward direction as positive), we have

$\varepsilon u_{\mathrm{g}}+(1-\varepsilon) u_{\mathrm{s}}=0$

where $u_{\mathrm{g}}$ is the upward velocity of the gas. Now in the same bed of particles in the fluidized state, the superficial gas velocity is given by

$U=\varepsilon\left(u_{\mathrm{g}}-u_{\mathrm{s}}\right)$

so that

$U=\frac{\varepsilon u_{\mathrm{g}}}{(1-\varepsilon)}=-u_{s}$

Hence the superficial gas velocity necessary to expand a bed to a given voidage is equal to the velocity at which that bed settles once the gas supply is turned off. By determining $U=f(\varepsilon)$, we therefore determine $u_{\mathrm{s}}=f(\varepsilon)$, the hindered settling function for the material. This is valid if all particles settle at the same speed, as in a monodisperse powder or in a polydisperse powder in which settling takes place en masse, the latter being the case in this paper.

\section{Experimental materials}

Three pyroclastic flow materials from France were used in the experiments: (1) a 0.58 -Ma trachytic ignimbrite from Neschers, $30 \mathrm{~km}$ south of Clermont-Ferrand (sample NES), (2) a 2.5-Ma rhyolitic ignimbrite from Rochfort Montagne in the Monts Dore (DOR), and (3) a 11-ka block-and-ash flow deposit from the Puy de Dôme, west of ClermontFerrand (PDD).

The dried materials each exhibited the segregation behaviour described by Wilson $(1980,1984)$ when fluidized at room temperature. Above $U_{\mathrm{mp}}$ the gas concentrated into segregation channels that persisted to the highest velocities used $\left(\sim 8 \mathrm{~cm} \mathrm{~s}^{-1}\right)$. Stirring the bed caused the channels to collapse, generating two layers of approximately equal thickness: a lower layer enriched in coarse/dense components and an upper one enriched in fine/light components. In each case the lower layer was vertically graded, whereas the upper was not. For each of the three materials the upper layer was separated off, and two size fractions, $<4 \mathrm{~mm}$ and $<250 \mu \mathrm{m}$, were used in the experiments (Table 1). Each sub-250 $\mu \mathrm{m}$ sample had a smaller mean particle size and higher fines $(<63 \mu \mathrm{m})$ content than its corresponding sub-4 mm sample (Table 1). Particles in PDD were denser and more equant in shape than those in NES or DOR, and DOR contained more fibrous pumice than NES (Table 1; Fig. 2).

No size or density segregation occurred in any of the six samples when fluidized, even at high velocities. This made it possible to interpret the experimental results quantitatively, while preserving essential features of the raw materials such as poor sorting and low permeability. While elutriation occurred at $U>U_{\mathrm{mb}}$, the loss of mass was not significant on the timescale of the experiments.

Operating temperatures ranged from 50 to $550^{\circ} \mathrm{C}$. A minimum of $50^{\circ} \mathrm{C}$ was required to avoid humidity-related cohesion (Druitt et al. 2004); sintering occurred above $\sim 550^{\circ} \mathrm{C}$. For each experiment a fresh batch of material was used. It was first oven-dried at $200^{\circ} \mathrm{C}$ for at least $12 \mathrm{~h}$, then transferred as quickly as possible $(\sim 5 \mathrm{~min})$ to the fluidization rig. The bed was then brought to temperature over $1-2 \mathrm{~h}$ in a weak flow of nitrogen. While it is common in fluidization studies to first condition the bed by prolonged gas flow in order to loosen the structure and break down clusters, this was not done because it would have caused too much elutriation. No attempt was made to 
Table 1 Particle size and density data of the experimental materials

\begin{tabular}{|c|c|c|c|c|c|c|c|c|c|c|c|}
\hline & \multicolumn{4}{|c|}{ Neschers ignimbrite } & \multicolumn{4}{|c|}{ Mont Dore ignimbrite } & \multicolumn{3}{|c|}{ Puy de Dôme block and ash flow } \\
\hline & $\begin{array}{l}\text { Granulomet } \\
(\mathrm{wt} . \%)^{\mathrm{a}}\end{array}$ & & $P: C: L^{b}$ & $\begin{array}{l}\text { Particle } \\
\text { Density }^{\mathrm{c}} \\
\mathrm{kg} \mathrm{m}^{-3}\end{array}$ & $\begin{array}{l}\text { Granulometry } \\
(\text { wt. } \%)^{\mathrm{a}}\end{array}$ & & $P: C: L^{b}$ & $\begin{array}{l}\text { Particle } \\
\text { Density } \\
\mathrm{kg} \mathrm{m}^{-3}\end{array}$ & $\begin{array}{l}\text { Granulometry } \\
(\text { wt. } \%)^{\mathrm{a}}\end{array}$ & & $\begin{array}{l}\text { Particle } \\
\text { Density }^{\mathrm{c}} \\
\mathrm{kg} \mathrm{m}^{-3}\end{array}$ \\
\hline$\mu \mathrm{m}$ & NES 4000 & NES 250 & & & DOR 4000 & DOR 250 & & & PDD 4000 & PDD 250 & \\
\hline 2,000 & 1.9 & & $100: \operatorname{Tr}: \operatorname{Tr}$ & 610 & 2.7 & & 100:Tr:Tr & 740 & 4.5 & & 1,310 \\
\hline 1,000 & 2.7 & & $96: 2: 2$ & 855 & 5.0 & & $98: 1: 1$ & 860 & 4.6 & & 1,300 \\
\hline 500 & 5.1 & & $89: 5: 6$ & 1,070 & 7.3 & & $91: 7: 2$ & 1,020 & 4.7 & & 1,270 \\
\hline 250 & 9.8 & & $67: 28: 5$ & 1,270 & 14.7 & & $87: 12: 1$ & 1,050 & 7.3 & & 1,425 \\
\hline 125 & 13.7 & 17.0 & & 1,495 & 19.1 & 27.2 & & 1,430 & 15.8 & 20.0 & 1,615 \\
\hline 63 & 16.3 & 20.2 & & 1,525 & 22.3 & 31.7 & & 1,540 & 21.9 & 27.8 & 1,700 \\
\hline 32 & 16.2 & 20.1 & & & 13.4 & 19.1 & & & 20.7 & 26.2 & \\
\hline 16 & 15.7 & 19.5 & & & 6.7 & 9.5 & & & 12.1 & 15.3 & \\
\hline 8 & 9.6 & 11.9 & & & 4.0 & 5.7 & & & 4.5 & 5.7 & \\
\hline 4 & 4.7 & 5.8 & & & 2.5 & 3.6 & & & 1.2 & 1.5 & \\
\hline 2 & 2.3 & 2.9 & & & 1.3 & 1.8 & & & 0.5 & 0.6 & \\
\hline 1 & 1.4 & 1.7 & & & 0.8 & 1.1 & & & 0.2 & 0.3 & \\
\hline$<1$ & 0.6 & 0.7 & & & 0.2 & 0.3 & & & 2.0 & 2.5 & \\
\hline$<63$ & 50.5 & 62.7 & & & 28.9 & 41.1 & & & 41.2 & 52.2 & \\
\hline Mean $^{\mathrm{d}}$ & 4.0 & 4.7 & & & 3.1 & 4.0 & & & 3.5 & 4.1 & \\
\hline Sorting $^{\mathrm{d}}$ & 2.29 & 1.75 & & & 2.11 & 1.55 & & & 2.14 & 1.41 & \\
\hline Voidage $^{e}$ & 0.42 & & & & 0.35 & & & & 0.50 & & \\
\hline
\end{tabular}

${ }^{a}$ Grain size analyses by dry sieving from 2,000 to $63 \mu \mathrm{m}$, and by Malvern laser Mastersizer from 32 to $<1 \mu \mathrm{m}$

${ }^{\mathrm{b}} \mathrm{P}: \mathrm{C}: \mathrm{L}$ : Pumice : crystal: lithic percentages

${ }^{\mathrm{c}}$ Particle density estimated as follows. One-phi size fractions from 2,000 to $63 \mu \mathrm{m}$ were sieved, dried and weighed. The volumes corresponding to the loosest possible packing of each size fraction were measured, and the corresponding bulk densities calculated. Estimates were then made of the mean particle density for each size fraction. To do this required an estimate of the intergranular voidage for each size fraction. Each size fraction was thoroughly soaked with silicone spray, then dried. Water was then added, while mixing, until the granular framework was just saturated. The material was then weighed in order to determine the mass of water, and the intergranular voidage was calculated. Silicone spray prevented infiltration of water into the particles, so that the voidage measured was that between the grains and did not include the porosity of the particles themselves. This was confirmed by visual inspection, which showed that water penetration into the porous particles was very limited. ${ }^{\mathrm{d}}$ Grain-size parameters Mz and $\sigma \mathrm{I}$ of Folk and Ward (1957)

${ }^{\mathrm{e}}$ Intergranular (hydrodynamic) voidage was estimated using (1) the sample particle size distribution, (2) particle density values for each size fraction, and (3) sample bulk density. Errors $( \pm 0.03)$ reflect uncertainties on particle densities for the $<63 \mu \mathrm{m}$ fractions. For comparison, voidages of silicon carbide mixtures with similar grain-size distributions to our three $<4 \mathrm{~mm}$ samples are approximately 0.5 .

control electrostatic effects in the experiments (Ciborowski and Wlodarski 1962).

\section{Expansion behaviour (experiment set 1)}

These experiments investigated the regime $U_{\mathrm{mb}}>U>U_{\mathrm{mp}}$ in which the samples expanded uniformly when stirred (Druitt et al. 2004). They provided measurements of parameters $U_{\mathrm{mp}}, U_{\mathrm{mb}}, H_{\mathrm{mp}}$ and $H_{\mathrm{mb}}$ (Fig. 1a). Operating temperatures ranged from 50 to $200^{\circ} \mathrm{C}$.

\section{Procedure}

The experiments were carried out in a 40-cm-high pyrex rig with a $20 \mu \mathrm{m}$ porous distributor plate. The windbox and fluidization chamber were surrounded by heating mats, while a vertical window allowed visual observation of the sample. The gas flux was measured by rotameters; nitrogen was used as the fluidizing gas to ensure negligible humidity. The sample mass in all experiments was $1.25 \mathrm{~kg}$.

Exploratory runs were carried out at $130 \pm 30^{\circ} \mathrm{C}$ to determine the general behaviour of the materials; more precise experiments were then done at $55 \pm 10^{\circ} \mathrm{C}$ and $200 \pm$ $10^{\circ} \mathrm{C}$. $U_{\mathrm{mp}}$ was estimated using the velocity at which the bed began to expand, lost friction and could be stirred, since the rig was not fitted with pressure transducers. Above $U_{\mathrm{mp}}$ the following procedure was adopted (Fig. 3). Gas velocity was increased incrementally as the bed was stirred with a metal spatula. At each velocity, the bed height was measured while stirring. Stirring was then stopped, and the height re-measured immediately, then 10-20 s later when it had stabilized in the non-agitated state. Velocity was then increased again and the process repeated. Once 

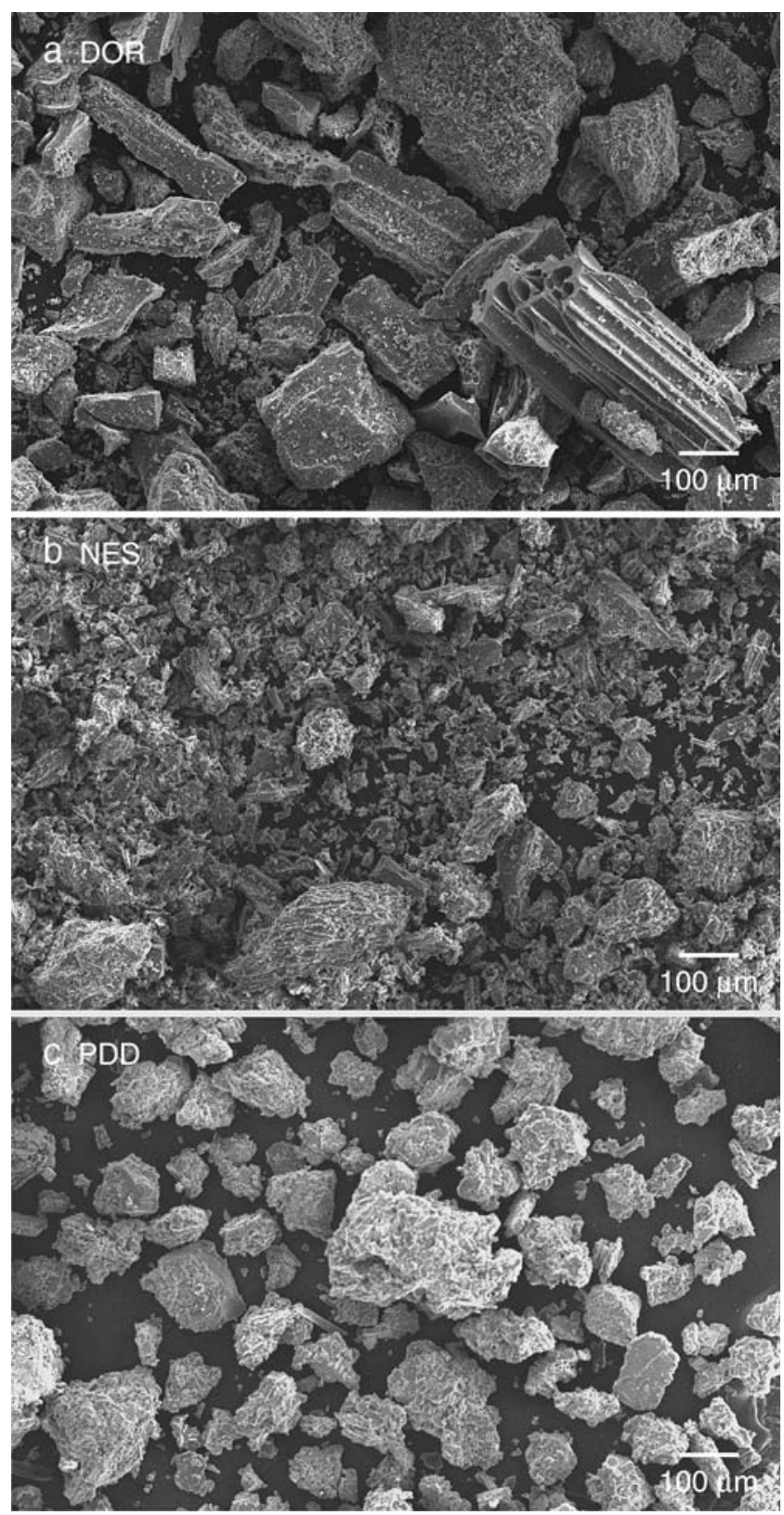

Fig. 2 Scanning electron microscope images of ash particles from the samples of this study. a Ignimbrite DOR, b ignimbrite NES, c blockand-ash flow deposit PDD. The scale bar is $100 \mu \mathrm{m}$. DOR had a higher proportion of fibrous pumice than NES. Particles in PDD were denser than those of DOR and NES

the bed was in a state of fully turbulent fluidization, measurements were then repeated as the gas velocity was decreased to zero. Differences between up-velocity and down-velocity curves were not significant.

Results

Representative up-velocity results for samples NES and PDD are shown in Fig. 3; the expansion behaviours are summa- rized schematically in Fig. 4. Values of $U_{\mathrm{mp}}$ ranged from 0.1 to $0.5 \mathrm{~cm} \mathrm{~s}^{-1}$, and $U_{\mathrm{mb}}$ ranged from 0.4 to $1.5 \mathrm{~cm} \mathrm{~s}^{-1}$. The ratio $U_{\mathrm{mb}} / U_{\mathrm{mp}}$ varied from 2 to 8 . $U_{\mathrm{mb}}$ was defined as follows (Fig. 4).

Sub-4 mm samples (1) $U_{\mathrm{mb}}>U>U_{\mathrm{mp}}$. Stirring resulted in uniform expansion; gas channels developed over a few seconds once stirring ceased. (2) $U>U_{\text {mb }}$. Stirring resulted in uniform expansion, but when it was stopped the bed inflated rapidly and bubbling set in, causing elutriation. The bubbling then died down over $\sim 10 \mathrm{~s}$ as gas channels formed.

Sub-250 $\mu$ m samples (1) $U_{\mathrm{mb}}>U>U_{\mathrm{mp}}$. Stirring induced local bubbling around the spatula. When stirring was ceased, the bed stopped bubbling and inflated uniformly before then slowly deflating as gas channels formed. (2) $U>U_{\mathrm{mb}}$. The behaviour was similar except that bubbling continued even after stirring was stopped.

In all samples stirring served to suppress gas channelling. Stirring also suppressed bubble formation in the sub$4 \mathrm{~mm}$ samples, but promoted it in the sub-250 $\mu \mathrm{m}$ samples.

The ratio $H_{\mathrm{mb}} / H_{\mathrm{mp}}$ provided a measure of the width of the uniform expansion regime (Fig. 5). Mean values for the samples ranged from 1.1 to 1.6, with three clear trends in the data. First, $H_{\mathrm{mb}} / H_{\mathrm{mp}}$ was higher in each sub-250 $\mu \mathrm{m}$ sample than in its corresponding sub-4 mm sample. For example, values for NES 250 were 1.5-1.6, while those for NES 4000 were 1.3-1.4. Second, values for PDD were lower than those for DOR or NES at a given size fraction. Third, raising temperature from 55 to $200^{\circ} \mathrm{C}$ increased $H_{\mathrm{mb}} / H_{\mathrm{mp}}$.

The function most commonly used to describe the expansion of a gas-particle mixture is (Richardson and Zaki 1954)

$U=U_{\mathrm{t}} \varepsilon^{n}$

where $U_{\mathrm{t}}$ is the terminal velocity of a single particle at $\varepsilon=1$, and $n$ is a constant for a particular material under given conditions. A problem in applying this or any other expansion relationship involving $\varepsilon$ (e.g., Abrahamsen and Geldart 1980a; their Eq. 23) to pyroclastic materials is that it requires accurate estimation of $\varepsilon$, which is difficult in powders composed of variably porous particles. Crude estimates of $\varepsilon$ for our materials are given in Table 1, but they are not precise enough to warrant quantitative use. We therefore derive an approximation of Eq. 8 that avoids voidage. Writing $U_{\mathrm{mp}} \approx U_{\mathrm{t}} \varepsilon_{\mathrm{mp}}^{n}$ and substituting into Eq. 8 gives $U \approx U_{\mathrm{mp}}\left(\varepsilon^{n} / \varepsilon_{\mathrm{mp}}^{n}\right)$. Now for values of $\varepsilon$ in the range 

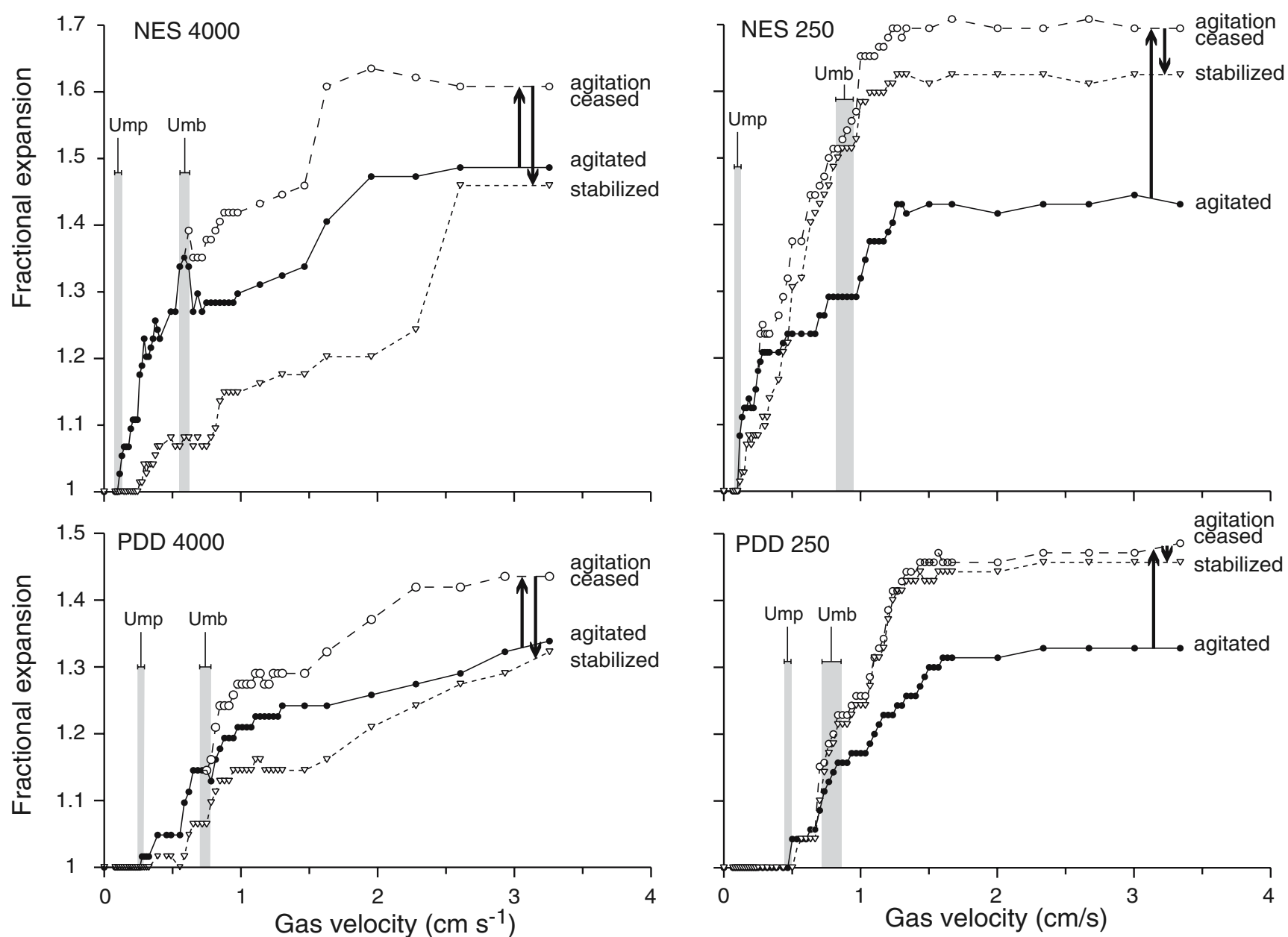

Fig. 3 Expansion of NES and PDD samples when gas velocity was increased while gently stirring at $\sim 130^{\circ} \mathrm{C}$ (experiment set 1 ). $U_{\mathrm{mp}}$ in these experiments was the velocity at which the bed began to expand and could be stirred. $U_{\mathrm{mb}}$ was the onset of visible bubbling. For every

$0.4-0.6$, we have that $H / H_{\mathrm{mp}} \approx\left(1-\varepsilon_{\mathrm{mp}}\right) /(1-\varepsilon) \approx \varepsilon /$ $\varepsilon_{\mathrm{mp}}$, so we can write

$U \approx U_{\mathrm{mp}}\left(\frac{H}{H_{\mathrm{mp}}}\right)^{n}$

An advantage of this expression is that $U$ is expressed solely as a function of measurable parameters. Another is that, by applying Darcy's Law, the effective permeability of the expanded bed can be expressed simply as

$K \approx K_{\mathrm{mp}}\left(\frac{H}{H_{\mathrm{mp}}}\right)^{n}$

Plots of $\ln \left(U / U_{\mathrm{mp}}\right)$ versus $\ln \left(H / H_{\mathrm{mp}}\right)$ for our expansion data (bold curves in Fig. 4) do indeed generate sets of approximately straight lines (Fig. 6), showing that Eq. 9 is adequate for describing these complex materials. Sub$250 \mu \mathrm{m}$ samples yield $6>n>2$, and sub-4 $\mathrm{mm}$ samples yield $12>n>7$. There is no discernable influence of temperature.

value of velocity the state of the bed was recorded (1) during stirring, (2) immediately following cessation of stirring, and (3) once it had reached a stable, non-stirred state

In summary, a broad regime of uniform expansion was favoured by (a) smaller particle size, (b) lower particle density (and/or more equant particle shapes), and (c) higher temperature, and this is consistent both with published data on monodisperse powders and with theoretical predictions (Foscolo and Gibilaro 1984; Rapagna et al. 1994; Xie and Geldart 1995; Yates 1996; Lettieri et al. 2002). The highest uniform expansions were about $60 \%$. Fine-grained materials had low values of the Richardson-Zaki exponent, $n$, reflecting their ability to expand relatively easily when subjected to small increases in gas velocity. Adding coarser particles (at least up to $4 \mathrm{~mm}$ ) increased $n$.

\section{Settling behaviour (collapse tests; experiment set 2)}

These experiments studied the defluidization behaviour from $U>U_{\mathrm{mb}}$ through a series of collapse tests. They were carried out from 50 to $550^{\circ} \mathrm{C}$ and provided measurements 
a Samples $<4 \mathrm{~mm}$

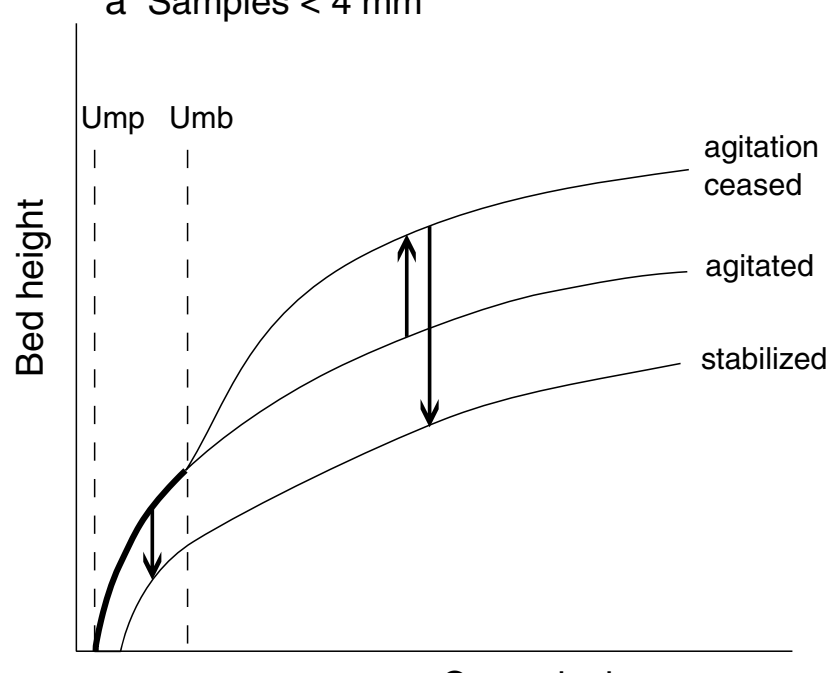

Gas velocity

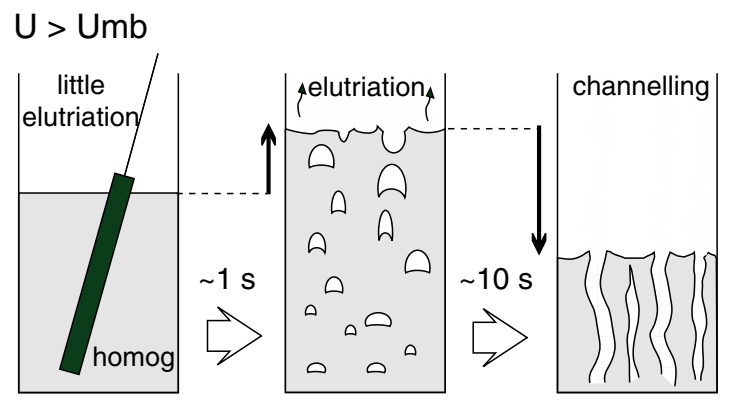

$\mathrm{Umb}>\mathrm{U}>\mathrm{Ump}$

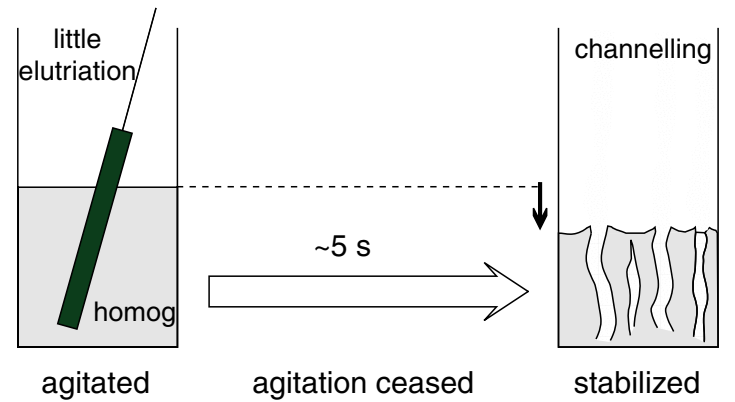

b Samples $<250 \mu \mathrm{m}$

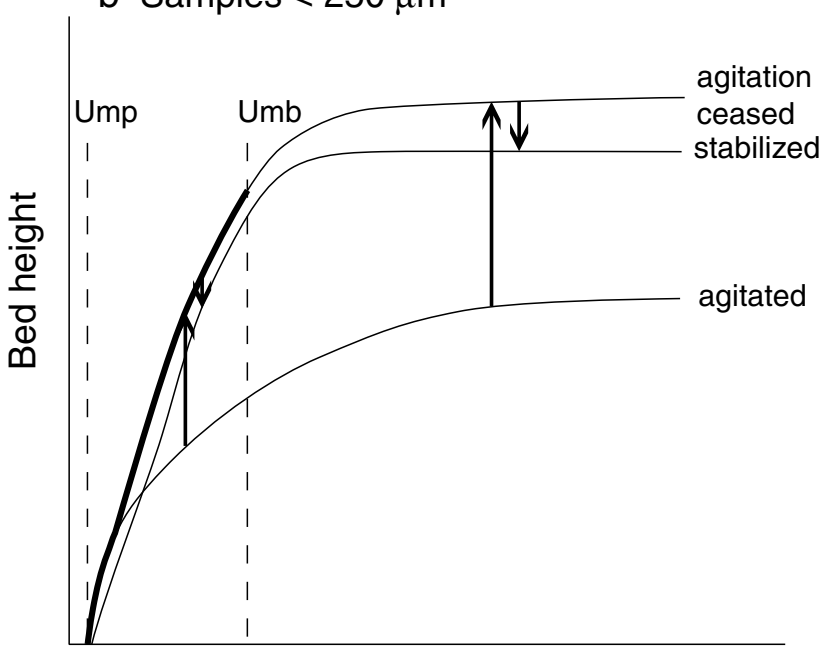

Gas velocity

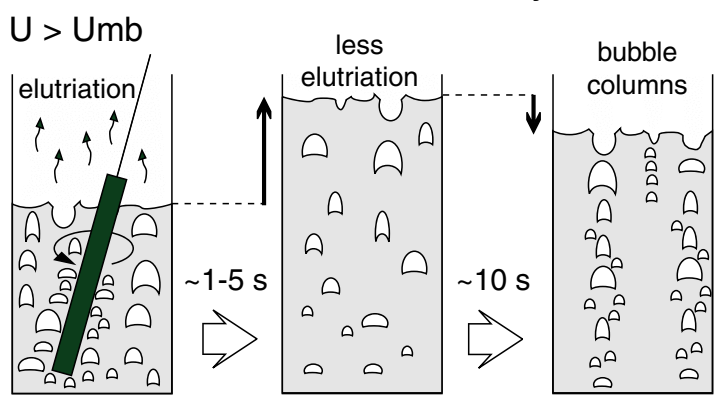

$\mathrm{Umb}>\mathrm{U}>\mathrm{Ump}$

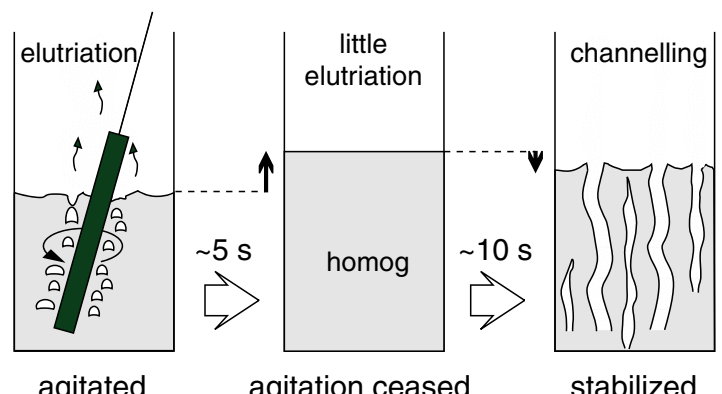

Fig. 4 Summary of the expansion behaviour observed in experiment set 1 . The bold parts of the curves were used to derive the hindered settling functions for these materials. See text for discussion

of $H_{\text {be }}, H_{\text {sett }}$ and $U_{\text {sett }}$ (Fig. 1b). $U_{\text {sett }}$ is the hindered settling velocity; $H_{\mathrm{be}}$ is the bed height immediately following bubble evacuation and is a measure of the expansion of the dense phase in the bubbling bed. $H_{\text {sett }}$ is the height of the settled bed. $U_{\mathrm{mp}}$ of the settled bed was also measured over the same temperature range for calculation of permeability.

\section{Procedure}

The experiments were carried out using an INOX fluidization rig, $1 \mathrm{~m}$ high and $14 \mathrm{~cm}$ in diameter, with a $20-\mu \mathrm{m}-$ pore distributor plate through which nitrogen was passed.
The gas flux was measured by rotameters and the pressure drop across the bed was measured by a pressure transducer. Two solenoid valves allowed the bed to be abruptly defluidized: one (V1) cut the gas supply and the other (V2) vented the gas trapped in the windbox. Since the rig was opaque, the bed was filmed at 25 frames per second using a pulsed, high-energy X-ray beam to image the surface, as well as bubbles and channels below the surface.

In each experiment $2.5 \mathrm{~kg}$ of sample was fluidized at high velocity before then cutting the gas supply and allowing the bed to re-sediment under its own weight. We chose a starting velocity of $8 \mathrm{~cm} \mathrm{~s}^{-1}$, at which the beds were fully supported and bubbling vigorously; halving or 


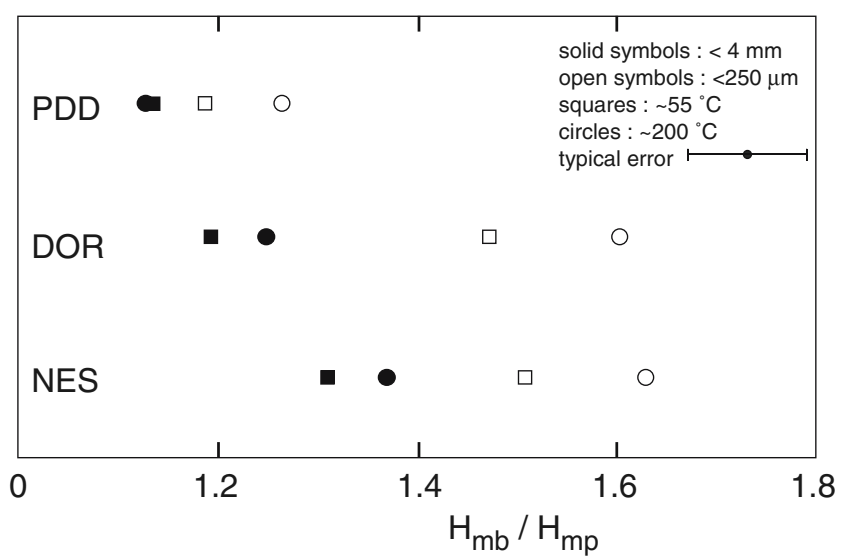

Fig. 5 Values of $H_{\mathrm{mb}} / H_{\mathrm{mp}}$ from experiment set 1

doubling this had no significant effect on the results. The bed was left in this state for about half a minute in order to stabilise, during which $<1$ wt. $\%$ of sample was lost by elutriation. The gas supply was then cut by closing valve V1 and simultaneously opening valve V2. In this so-called 'dual-drainage' configuration the gas escaped through the base of the windbox as well as upwards through the bed (Park et al. 1991; Cherntongchai and Brandani 2005). Bed height during collapse was measured as a function of time from the X-ray images and corrected for perspective effects and minor camera distortion. No stirring was required because collapse took place on a time scale too short for significant channelling to set in. In some runs gas pressure was monitored continuously by filming the transducer readout. The response time of the transducer was very fast compared with the duration of collapse.

$U_{\text {mp }}$ of the settled bed was measured immediately after collapse. Gas velocity was increased incrementally from zero while monitoring the pressure drop. Pressure increased as an almost linear function of velocity until a maximum was reached at $U_{\mathrm{mp}}$. The maximum pressure tolerated by the bed was the bed weight per unit area, $\Delta P_{\max }=M g / A$, where $M$ is the sample mass and $A$ is the surface area of the rig, although slight cohesion commonly caused this to be exceeded. $U_{\mathrm{mp}}$ was estimated by extrapolation in samples where channelling began prematurely before bed support was reached.
Fig. 6 Uniform expansion data of experiment set 1 plotted using Eq. (9) for a sub-250 $\mu \mathrm{m}$ samples, and b sub-4 mm samples. The grey area in (a) shows the data spread in (b), and vice versa
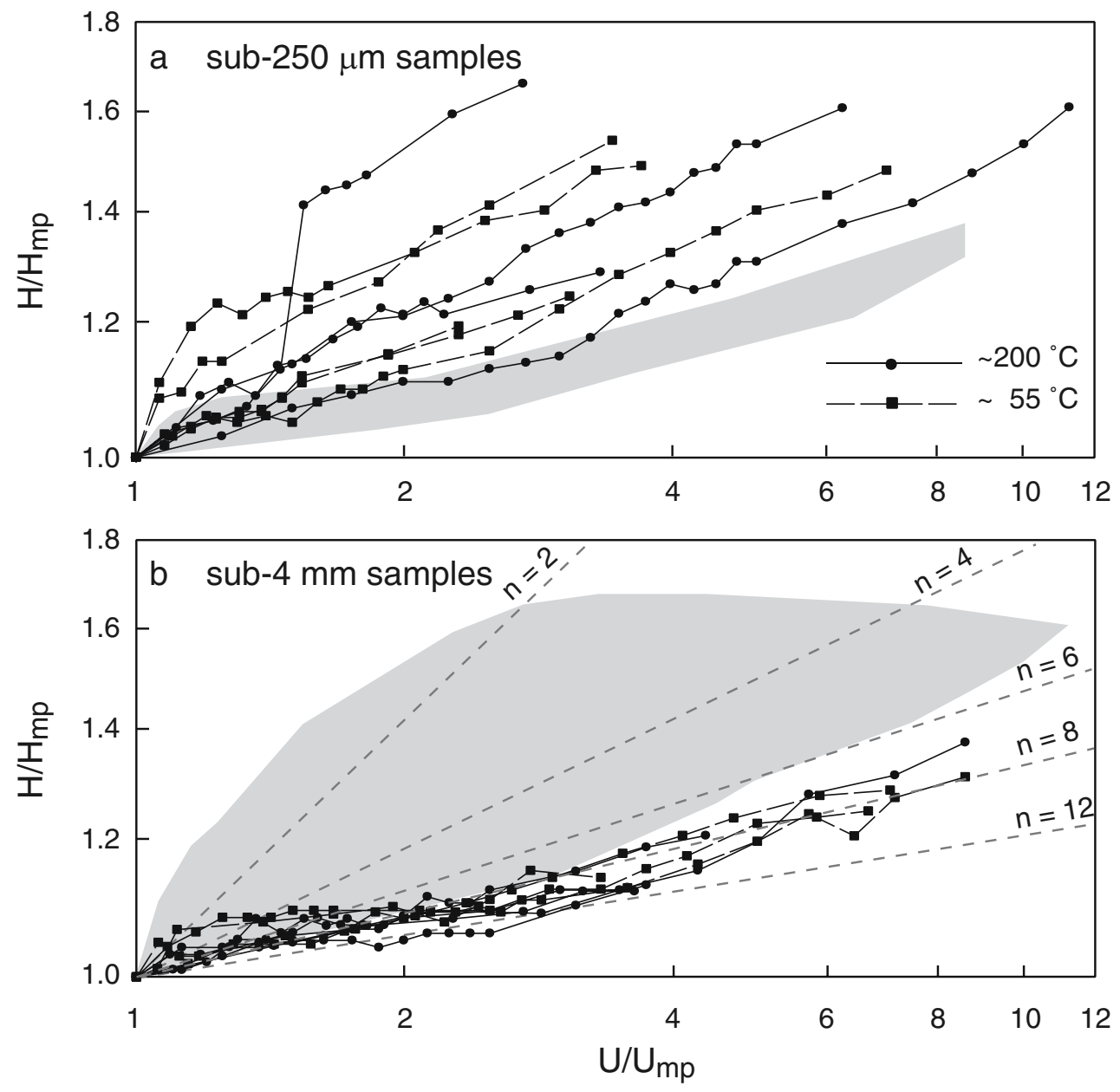

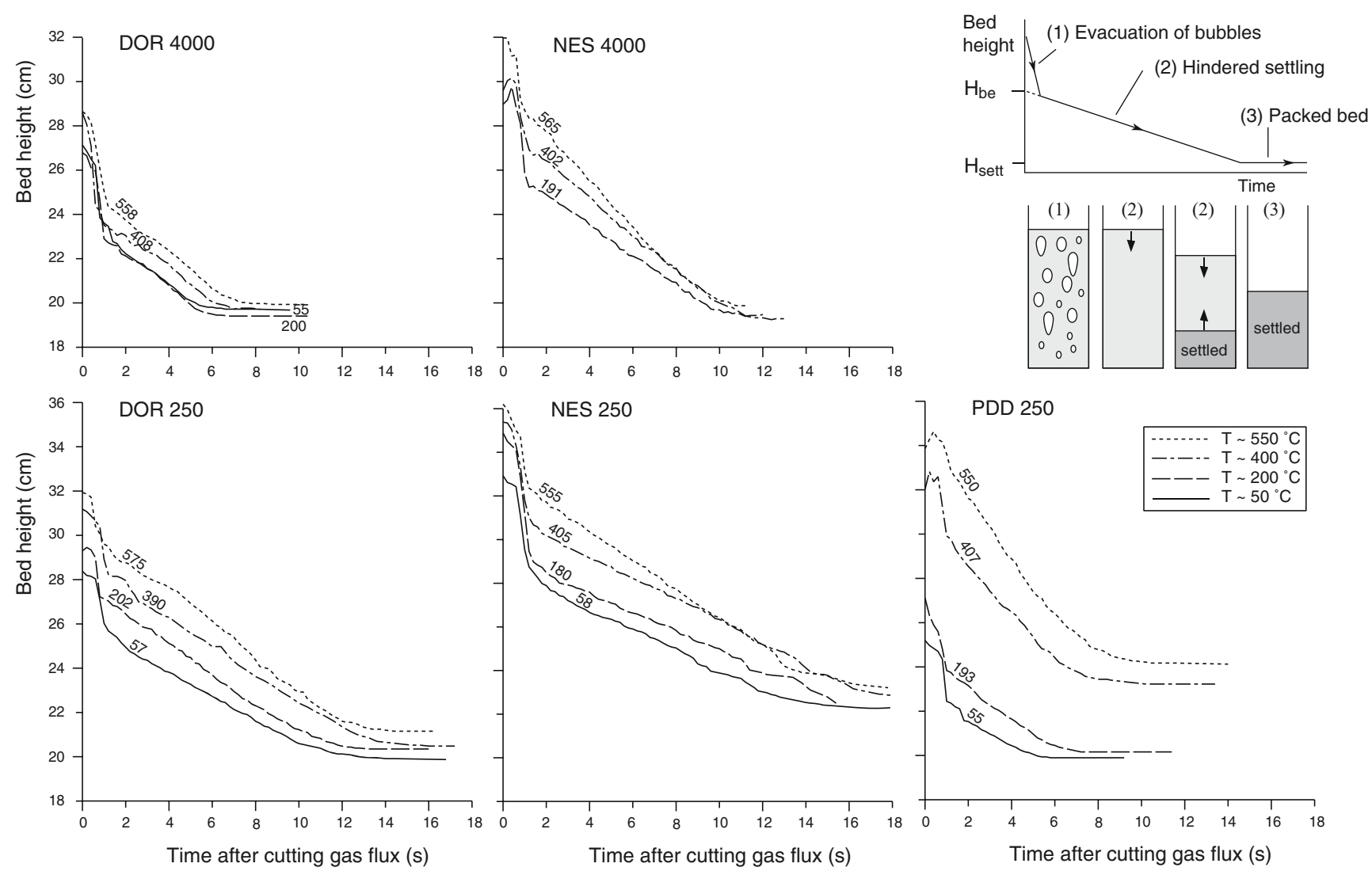

Fig. 7 Bed collapse curves at different temperatures (experiment set 2). Each curve has an initial steep segment due to bubble evacuation, followed by a shallower segment due to hindered settling. Individual data points omitted for clarity (sampling frequency $0.2 \mathrm{~s}$ )

Results

The results of these experiments are shown in Figs. 7, 8, and 9. Collapse times ranged from 5 to $18 \mathrm{~s}$, and the curves had the three segments characteristic of group-A powders (Geldart and Wong 1985): (1) a steep bubbleevacuation segment, (2) a shallower, hindered settling segment, and (3) a horizontal segment corresponding to the settled bed (Fig. 7). The sediment layer aggraded progressively at the base of the rig until settling was complete. Although the sediment layer was not visible on $\mathrm{X}$-ray images, the sharpness of the transition from segments 2 to 3 showed that the sediment had a welldefined surface. Late-stage compaction and channelling generated slight curvature of transition 2-3 (Fig. 7). The gas pressure drop across the bed decreased during collapse such that only about $10 \%$ of the initial pressure remained once settling was complete (Fig. 8). This showed that outgassing of the sediment occurred on a timescale that was short compared to that of particle settling.

Values of $H_{\mathrm{be}} / H_{\mathrm{mp}}$ ranged from 1.1 to 1.5 (Fig. 9) and were consistent with those of $H_{\mathrm{mb}} / H_{\mathrm{mp}}$ from experiment set 1 (Fig. 5). Moreover, like $H_{\mathrm{mb}} / H_{\mathrm{mp}}, H_{\mathrm{be}}$ and $H_{\mathrm{be}} / H_{\mathrm{mp}}$ both increased with temperature, as also observed in other powders (Abrahamsen and Geldart 1980b; Lettieri et al. 2000). It seems that high temperature enhanced gas flow through the dense phase of the bubbling bed, thereby increasing dense-phase expansion. The temperature dependence exhibited by PDD 250 was particularly marked (Fig. 9). Sub-250 $\mu \mathrm{m}$ samples had higher values of $H_{\mathrm{be}}$ than their corresponding sub-4 $\mathrm{mm}$ samples, but this was not the case for $H_{\mathrm{be}} / H_{\mathrm{mp}}$. The effect of particle size on dense-phase expansion was therefore ambiguous.

Hindered settling velocity $U_{\text {sett }}$ either increased or remained constant with increasing temperature. The strongest thermal effect was exhibited by PDD 250 and, to a lesser extent, by NES 4000 (Fig. 9). Interestingly these two samples also exhibited strong thermal dependences of $H_{\text {be }}$, suggesting a relationship between $U_{\text {sett }}$ and $H_{\text {be }}$. We infer that in these samples settling at higher temperatures took place from more expanded, and hence more permeable, initial states, and was therefore faster. Thermal dependence of $U_{\text {sett }}$ was therefore interpreted as a secondary effect due to the effect of temperature on densephase expansion.

The height of the settled bed immediately following collapse $\left(H_{\text {sett }}\right)$ was greater in the sub-250 $\mu$ m samples than in corresponding sub-4 $\mathrm{mm}$ ones, probably because the 
Fig. 8 Variations of bed expansion (dots) and normalized gas pressure (circles) during bed collapse for samples NES 250 and PDD 250. Gas pressure was measured $2.5 \mathrm{~cm}$ above the base of the bed and was followed by videoing the pressure transducer readout during collapse. It is normalized to lithostatic overburden. The reaction time of the transducer was essentially instantaneous. The data show that only about $10 \%$ of the original gas pressure was retained in the beds once settling was complete
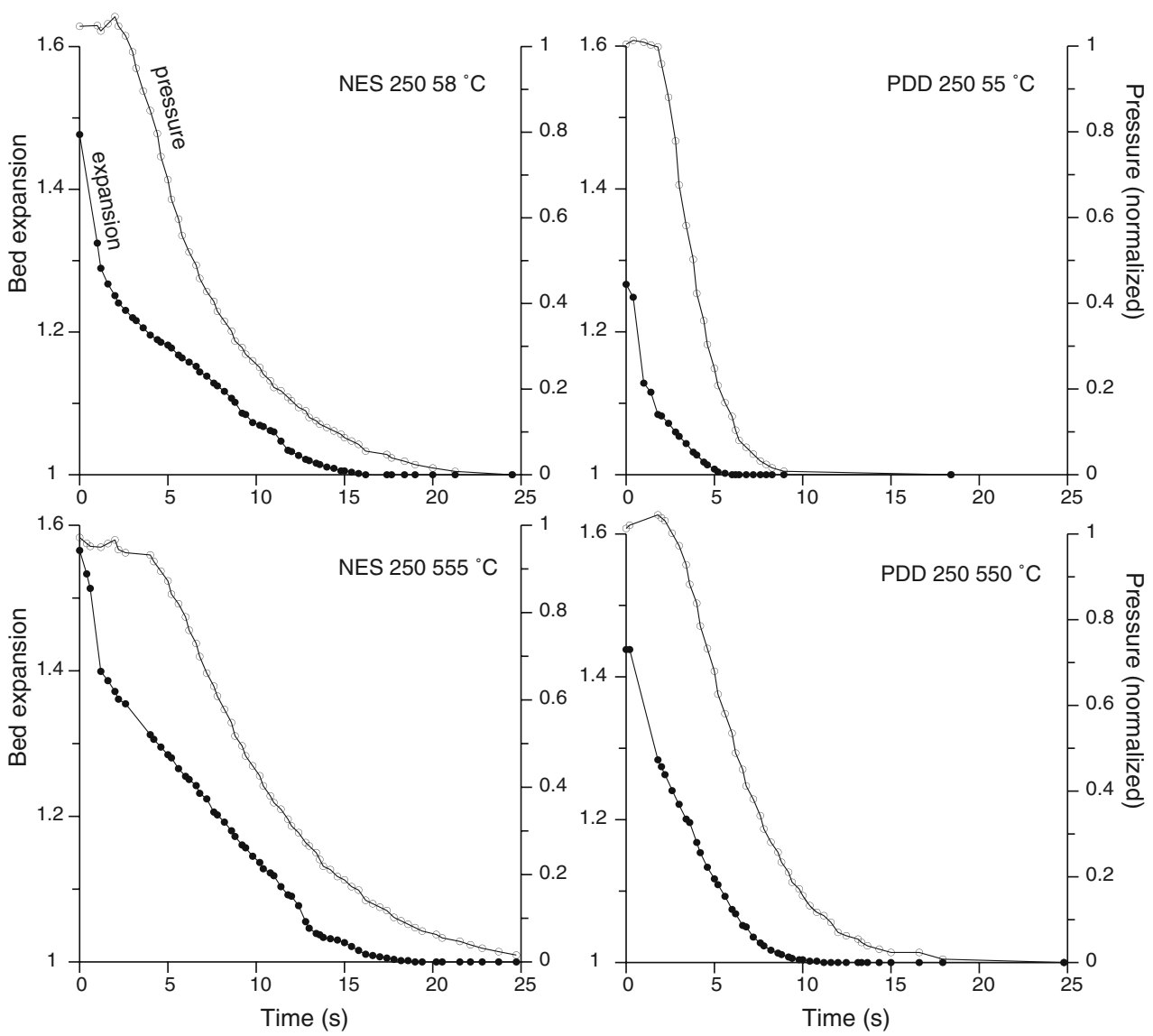

latter were more poorly sorted and finer particles partly filled interstices between coarser ones. An additional reason may have been that the sub-250 $\mu \mathrm{m}$ samples were richer in fines. Voidage in loosely packed powders is increased by high interparticle cohesion, the strength of which increases with decreasing particle size below $\sim 100 \mu \mathrm{m}$ (Yu et al. 2003).

Raising temperature had the effect of increasing $H_{\text {sett }}$, and hence voidage, in the sub- $250 \mu \mathrm{m}$ samples, particularly in PDD 250 (Fig. 9). In contrast, no systematic thermal effect was observed in the sub-4 $\mathrm{mm}$ samples. The tendency of high temperature to loosen packing and increase voidage has been reported from particles including silica sand, glass ballotini, salt and cracking catalyst (Botterill et al. 1982; Lucas et al. 1986; Raso et al. 1992; Yamazaki et al. 1995; Formisani et al. 1998; Lettieri et al. 2000, 2002). It has been attributed either to growth of cohesive forces (Raso et al. 1992; Yamazaki et al. 1995; Formisani et al. 1998) or to hydrodynamic effects related to the positive influence of temperature on gas viscosity (Lucas et al. 1986). However the fact that temperature affects voidage in the settled state $\left(H_{\text {sett }}\right)$, where there is no gas flow, rules out hydrodynamic effects in the case of our materials.
When the gas velocity was again increased following settling, the bed height remained constant up to $U_{\mathrm{mp}}$. Values of $H_{\mathrm{mp}}$ were therefore similar to those of $H_{\text {sett }}$ (Fig. 9). $U_{\mathrm{mp}}$ values remained constant or increased slightly with increasing temperature. This is in contrast with published data for $U_{\mathrm{mf}}$, which normally decreases with temperature by a factor of up to two between room temperature and several hundred ${ }^{\circ} \mathrm{C}$ (Lucas et al. 1986; Rapagna et al. 1994; Xie and Geldart 1995; Formisani et al. 1998; Lettieri et al. 2002). The decrease in $U_{\mathrm{mf}}$ is attributed to the approximate doubling of gas viscosity over this temperature range (see Eq. 20). However, this effect is partly counterbalanced in our samples by increase of voidage (through $H_{\mathrm{mp}}$ ), and hence permeability, at higher temperatures.

If the $H_{\mathrm{mp}}$ and $U_{\mathrm{mp}}$ data are recalculated in terms of bed permeability using Darcy's law

$U_{\mathrm{mp}} \approx \frac{K_{\mathrm{mp}}}{\mu}\left(M g / A H_{\mathrm{mp}}\right)$

an increase of $K_{\mathrm{mp}}$ with temperature is evident for all samples (Fig. 9). In Fig. 10 the values of $K_{\mathrm{mp}}$ at $\sim 50$ and 
a Maximum pressure conditions

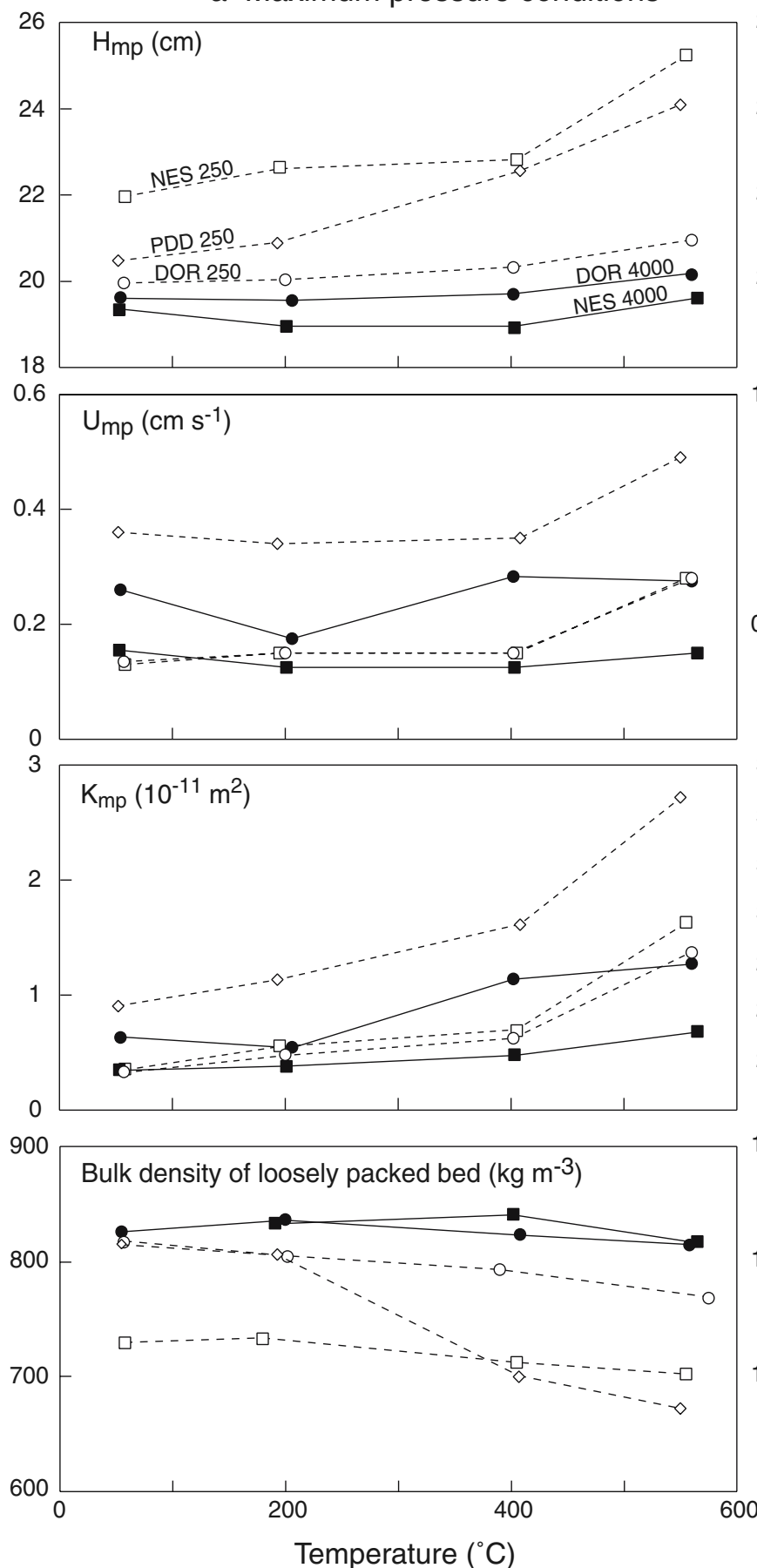

b Collapse conditions
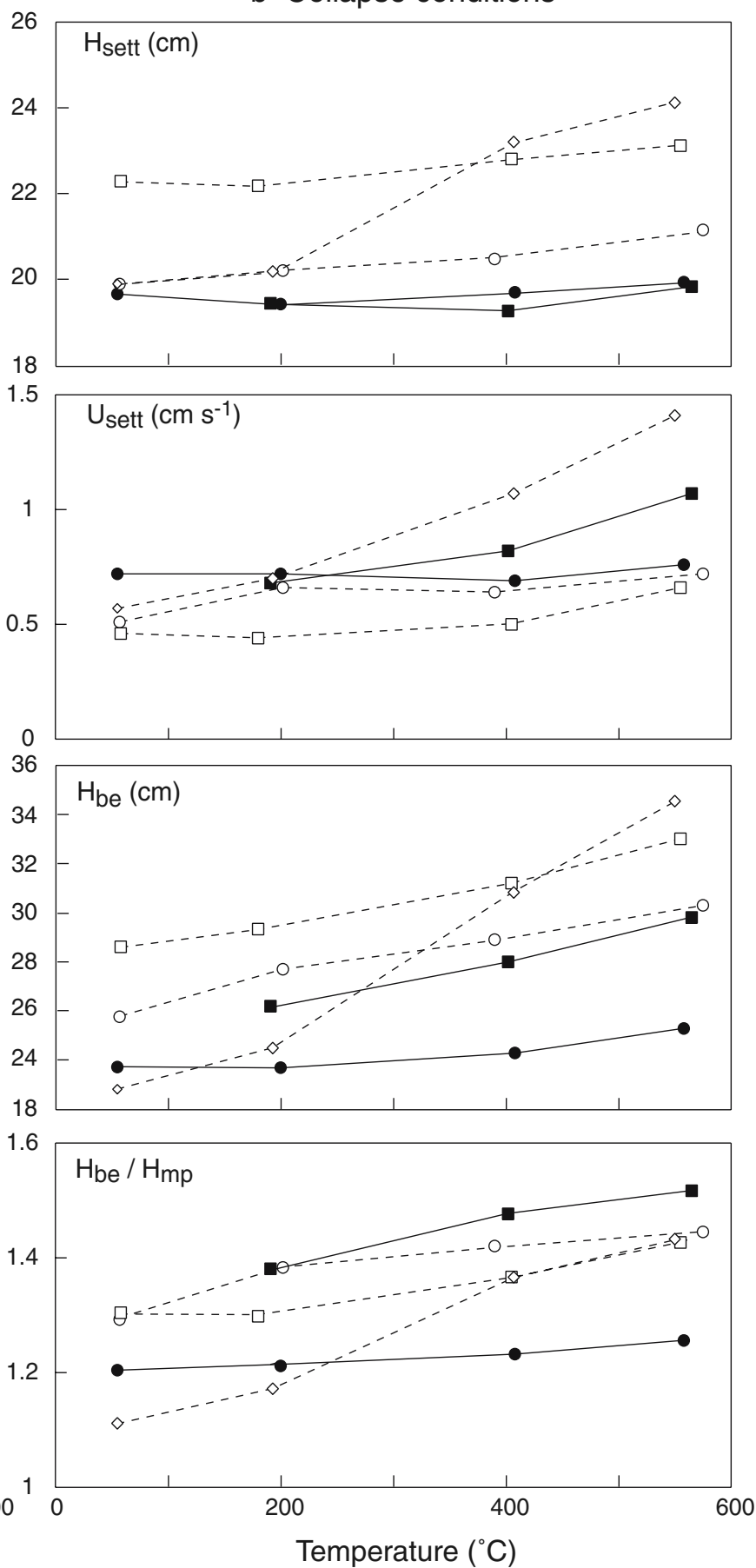

Fig. 9 Variation of fluidization and collapse parameters as functions of temperature, from experiment set 2. The parameters are defined in Fig. 1. The measurement errors on the heights are of the order of the symbol width. Those on velocities are several symbol widths

$\sim 550^{\circ} \mathrm{C}$ are plotted on the sorting-mean diagram of Wilson (1984), his parameter $U_{\mathrm{mp}}$ * being expressed as permeability. The $K_{\mathrm{mp}}$ values at $50^{\circ} \mathrm{C}$ are consistent with Wilson's data at room temperature, whereas those at $550^{\circ} \mathrm{C}$ are not. Increased temperature therefore has the effect of shifting the permeability boundaries upwards and to the right on this diagram.
In summary, high temperature favoured increased gas partitioning into the dense phase of the bubbling beds, increasing its expansion, whereas the effect of particle size distribution was not clear. For finer-grained samples, high temperature also resulted in increased voidage and permeability in the settled state, possibly due to thermal growth of cohesive forces. 
Fig. 10 Permeability $K_{\mathrm{mp}}$ plotted on the sorting-versus-mean figure of Wilson (1984). Wilson's data points are shown as white circles, and the contours of his parameter $U_{\mathrm{mp}} *$ at room temperature have been recalculated as permeability $\left(\mathrm{m}^{2}\right)$ using Darcy's Law. The black dots $(<250 \mu \mathrm{m}$ samples $)$ and squares ( $<4 \mathrm{~mm}$ samples) are data from the present study. In each case the number not in brackets is $K_{\mathrm{mp}}$ (units $10^{-11} \mathrm{~m}^{2}$ ) at $\sim 55^{\circ} \mathrm{C}$ and that in brackets is $K_{\mathrm{mp}}$ at $\sim 550^{\circ} \mathrm{C}$. Increased temperature shifts the contours as shown by the arrow. The sorting and mean parameters are taken from Table 1

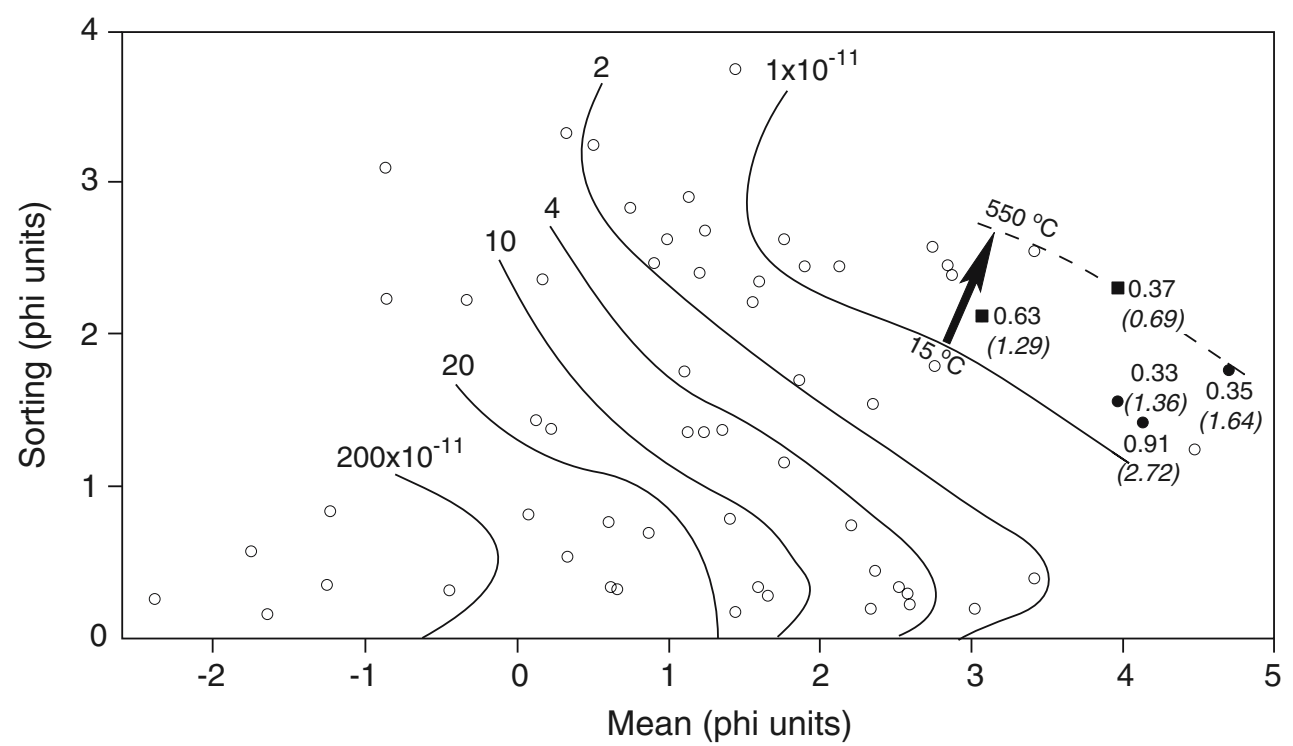

\section{Defluidization and gas retention}

The defluidization (collapse) behaviour of a gas-expanded bed is governed by three characteristic timescales: (1) $t_{\mathrm{be}}$, the time for bubble evacuation, (2) $t_{\text {sett, }}$ the time for hindered settling, and (3) $t_{\text {diff, the time for release of }}$ residual gas trapped in the sediment layer. We refer to these as the gas retention times. $t_{\mathrm{be}}$ is very short in our collapse tests (Fig. 7); its value probably depends on the size and ascent velocities of bubbles, which have not been studied here. We therefore neglect $t_{\mathrm{be}}$ in what follows.

We now present a 1-D numerical model of bed collapse and use it to explore in more detail the processes that take place during defluidization. We derive expressions for $t_{\text {sett }}$ and $t_{\text {diff, }}$, calculate their values for our materials, and extrapolate from laboratory to natural scales.

\section{Numerical model of a one-dimensional defluidizing bed}

The model assumes fully uniform behaviour and does not simulate bubbles. Defining $\mathrm{z}$ as positive upwards, the governing equations are (modified after Wallis 1969):

$\frac{\partial}{\partial t}\left(\varepsilon \rho_{\mathrm{g}}\right)+\frac{\partial}{\partial z}\left(\varepsilon \rho_{\mathrm{g}} u_{\mathrm{g}}\right)=0$

$\frac{\partial}{\partial t}\left((1-\varepsilon) \rho_{\mathrm{s}}\right)+\frac{\partial}{\partial z}\left((1-\varepsilon) \rho_{\mathrm{s}} u_{\mathrm{s}}\right)=0$

$\rho_{\mathrm{g}}\left(\frac{\partial u_{\mathrm{g}}}{\partial t}+u_{\mathrm{g}}\left(\frac{\partial u_{\mathrm{g}}}{\partial z}\right)\right)=-\rho_{\mathrm{g}} g+f_{\mathrm{g}}-\frac{\partial P}{\partial z}$ $\rho_{\mathrm{s}}\left(\frac{\partial u_{\mathrm{s}}}{\partial t}+u_{\mathrm{s}}\left(\frac{\partial u_{\mathrm{s}}}{\partial z}\right)\right)=-\rho_{\mathrm{s}} g+f_{\mathrm{s}}-\frac{\partial P}{\partial z}$

and the superficial velocity $U$ is given by Eq. 6. Equations 12 and 13 describe mass conservation, and Eqs. 14 and 15 describe momentum conservation. The drag terms are:

$f_{\mathrm{g}}=-\frac{\mu U}{K}$

$f_{\mathrm{s}}=f_{\mathrm{g}}+\left(\rho_{\mathrm{s}}-\rho_{\mathrm{g}}\right) g \quad$ if $U<U_{\mathrm{mp}}$

$f_{s}=\frac{\mu U}{K}\left(\frac{\varepsilon}{1-\varepsilon}\right) \quad$ if $U \geq U_{m p}$

Gas density and viscosity are given by the ideal gas law and Sutherlands formula

$\rho_{\mathrm{g}}=\frac{P}{\mathrm{r} T}$

$\frac{\mu}{\mu_{R}}=\left(\frac{T}{T_{R}}\right)^{3 / 2}\left(\frac{T_{R}+S}{T+S}\right)$

where $\mathrm{r}$ is the gas constant, $T$ is absolute temperature, $\mu_{R}$ is a reference viscosity, $T_{\mathrm{R}}$ is a reference temperature $(273 \mathrm{~K})$ and $\mathrm{S}$ is a constant. The values of $r, \mu_{\mathrm{R}}$, and $\mathrm{S}$ for nitrogen are $296.8 \mathrm{~J} \mathrm{~kg}^{-1} \mathrm{~K}^{-1}, 1.71 \times 10^{-5} \mathrm{~Pa} \mathrm{~s}$ and $110.4 \mathrm{~K}$, respectively.

Equations $12-15$ were simplified by ignoring inertial terms and solved using an adaptive time increment

$\Delta t=\frac{\varepsilon \mu \Delta z^{2}}{\tau K P}$ 
Fig. 11 Calculated profiles of gas pressure, voidage and gas velocity in a 4-m-thick, non-expanded bed outgassing from an initial state of $U=U_{\mathrm{mp}}$. Permeability $K_{\mathrm{mp}}$ is taken as $10^{-11} \mathrm{~m}^{2}$ and the time increment is $50 \mathrm{~s}$. The bold lines show the state of each bed at time zero, and the numbers are time in seconds

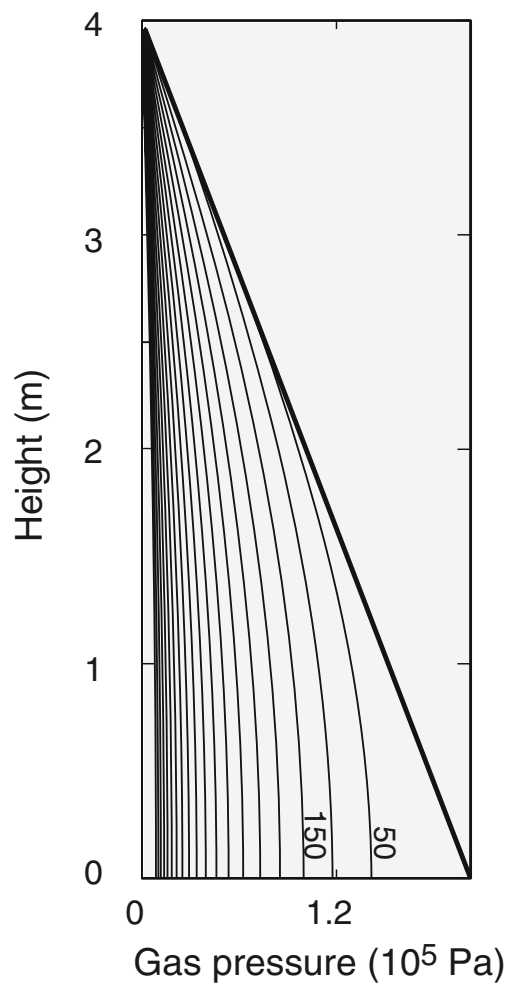

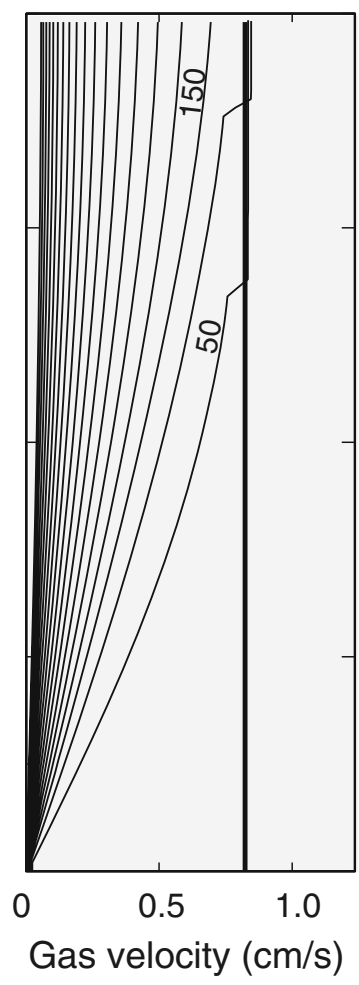

where $\tau$ is a constant. Calculations were carried out using $\Delta z=H / 100$; a value of $\tau=2$ was sufficient for stable solutions. Unlike in the experimental collapses, the base of the numerical bed was impermeable, since this is more relevant to the natural system of interest. $K$ was parameterised using Eq. 10.

Bed initially just fluidized at $U=U_{m p}$ In the simplest case the bed is initially just fluidized at $U=U_{\mathrm{mp}}$ (Fig. 11). Since there is no expansion, outgassing proceeds purely by permeable flow through the touching particle framework and Eqs. 12, 14, 16 and 19 reduce to that for gas pressure diffusion in a porous medium (e.g., Tardos et al. 1985).

$\frac{\partial P}{\partial t}=\frac{K}{\mu \varepsilon} \frac{\partial}{\partial z}\left(P\left(\frac{\partial P}{\partial z}+\rho_{\mathrm{g}} g\right)\right)$

Defluidization starts at the base of the bed and proceeds upwards. Gas pressure and velocity decline steadily at all levels until outgassing is complete, the pressure gradient at all times being perpendicular to the impermeable base of the bed. Solutions taking into account powder compressibility are given by Murfitt and Bransby (1980) and Tardos et al. (1985).

Bed initially expanded at $U_{m b}>U>U_{m p}$ In this case defluidization takes place from the initially expanded state, so that particle settling and pressure diffusion take place simultaneously in the suspension and sediment phases, respectively. We consider two bed thicknesses: $0.2 \mathrm{~m}$ for a laboratory-scale bed (Fig. 12a) and $4 \mathrm{~m}$ for a bed of thickness more relevant to a pyroclastic flow (Fig. 12b), both being initially expanded by $50 \%$. When the gas supply is cut, a voidage wave passes up though each bed as collapse occurs and a layer of sediment aggrades at the base. In the $0.2 \mathrm{~m}$ bed, outgassing of the thickening sediment layer takes place faster than settling, so that no residual gas is retained once settling is complete. However, this is not the case for the $4 \mathrm{~m}$ bed, where excess gas continues to diffuse out of the sediment for some time after settling. As explained below, the relative magnitudes of $t_{\text {sett }}$ and $t_{\text {diff }}$ depend on the thickness of the bed, $t_{\text {diff }}$ being longer than $t_{\text {sett }}$ in thick beds.

Gas retention times

The timescale for particle settling is

$t_{\text {sett }}=\frac{\left(H-H_{\text {sett }}\right)}{U_{\text {sett }}}$

where $H$ is the initial bed thickness, $H_{\text {sett }}$ is the thickness of the settled bed, and $U_{\text {sett }}$ is hindered settling velocity. Engineers call $t_{\text {sett }}$ the 'bed collapse time' (Geldart and Wong 1985). The timescale for diffusive gas release is 
Fig. 12 Calculated profiles of gas pressure, voidage and gas velocity in beds outgassing from an initial state of $U=U_{\mathrm{mb}}$. Permeability is calculated as a function of expansion using Eq. 10, with values of $K_{\mathrm{mp}}=10^{-11} \mathrm{~m}^{2}$ and $n=3$, appropriate for fine-grained ignimbrite. The bold lines show each bed in its initial expanded state at time zero. In each case the initial suspension is expanded to a thickness 1.5 times that of the final, settled bed (shown in grey). Numbers are time in seconds. (a) Settled bed $0.5 \mathrm{~m}$ thick and time increment of $5 \mathrm{~s}$. (b) Settled bed $4 \mathrm{~m}$ thick and time increment of $100 \mathrm{~s}$
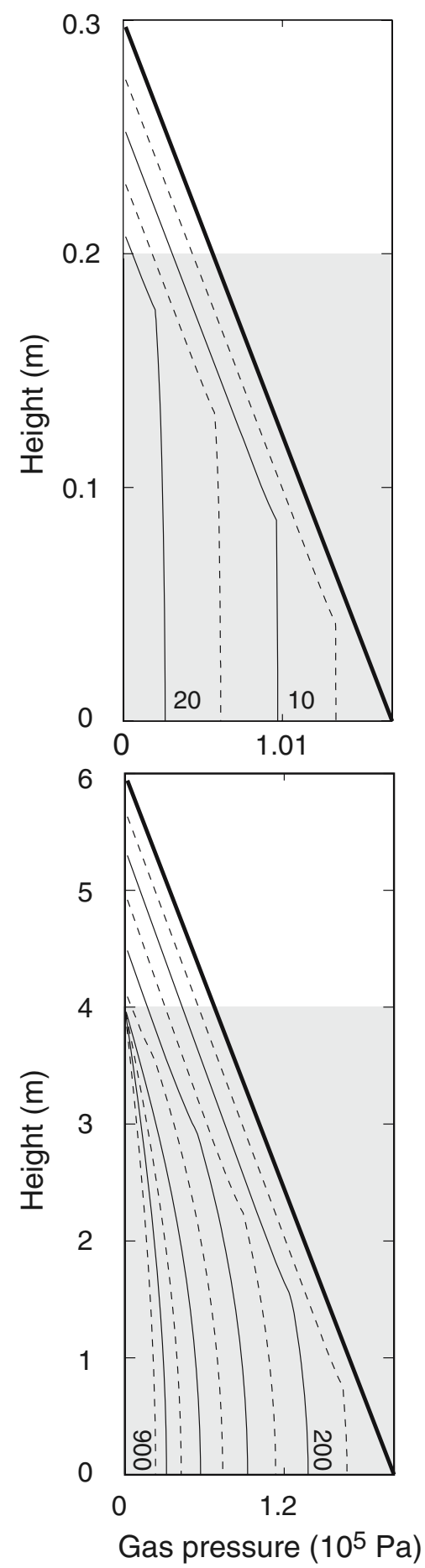
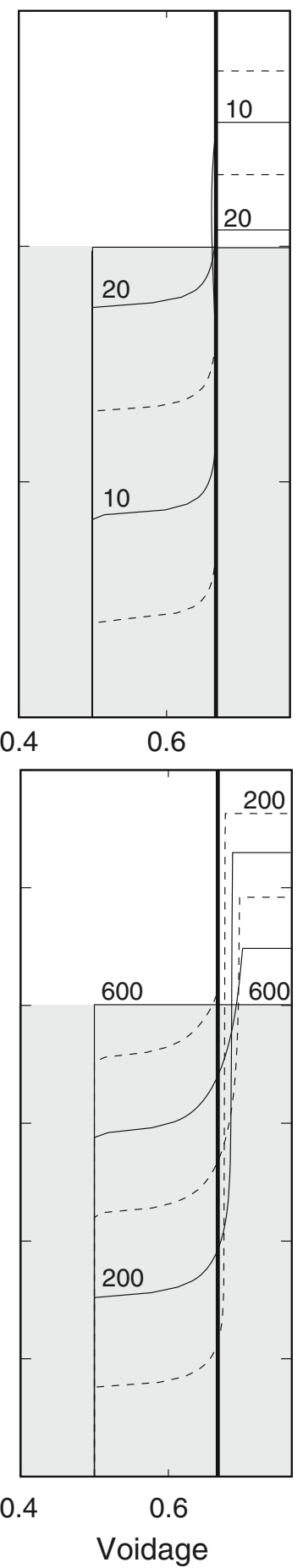
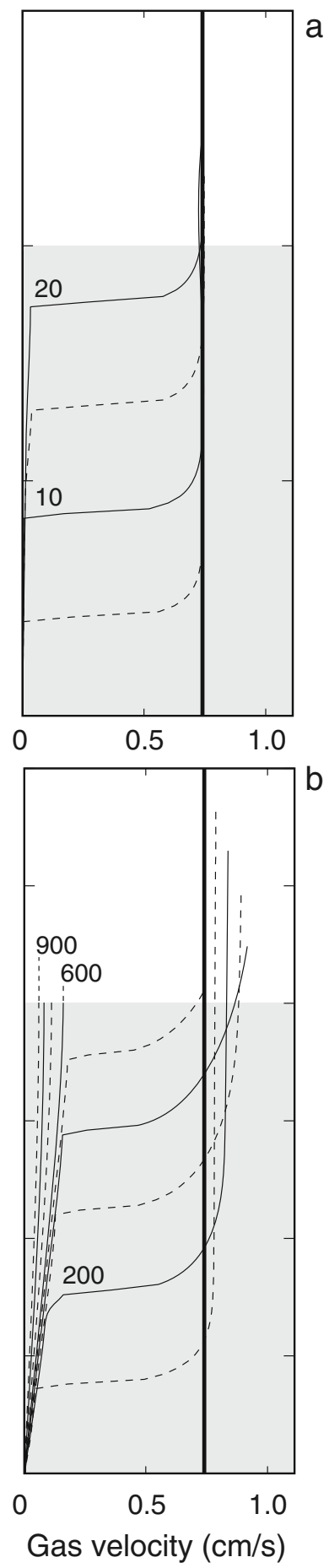

obtained by non-dimensionalizing $P$ by $P_{\text {atm }}$ and $z$ by $H$ in Eq. 22, yielding

$$
t_{\text {diff }}=\frac{\mu \varepsilon H^{2}}{K P_{\text {atm }}}
$$

Note that $P_{0}$, the initial pressure at the base of the bed, could also be chosen to non-dimensionalize $P$. However, since $P$ in Eq. 22 is an absolute value, scaling by a relative pressure, such as $P_{0}-P_{\text {atm }}$, would be incorrect. As written in Eq. $24, t_{\text {diff }}$ is the the time necessary for the basal pressure 
Fig. 13 Hindered settling and pressure diffusion times calculated from the collapse test data of experiment set 2 . The values are for a non-expanded bed height of $20 \mathrm{~cm}$
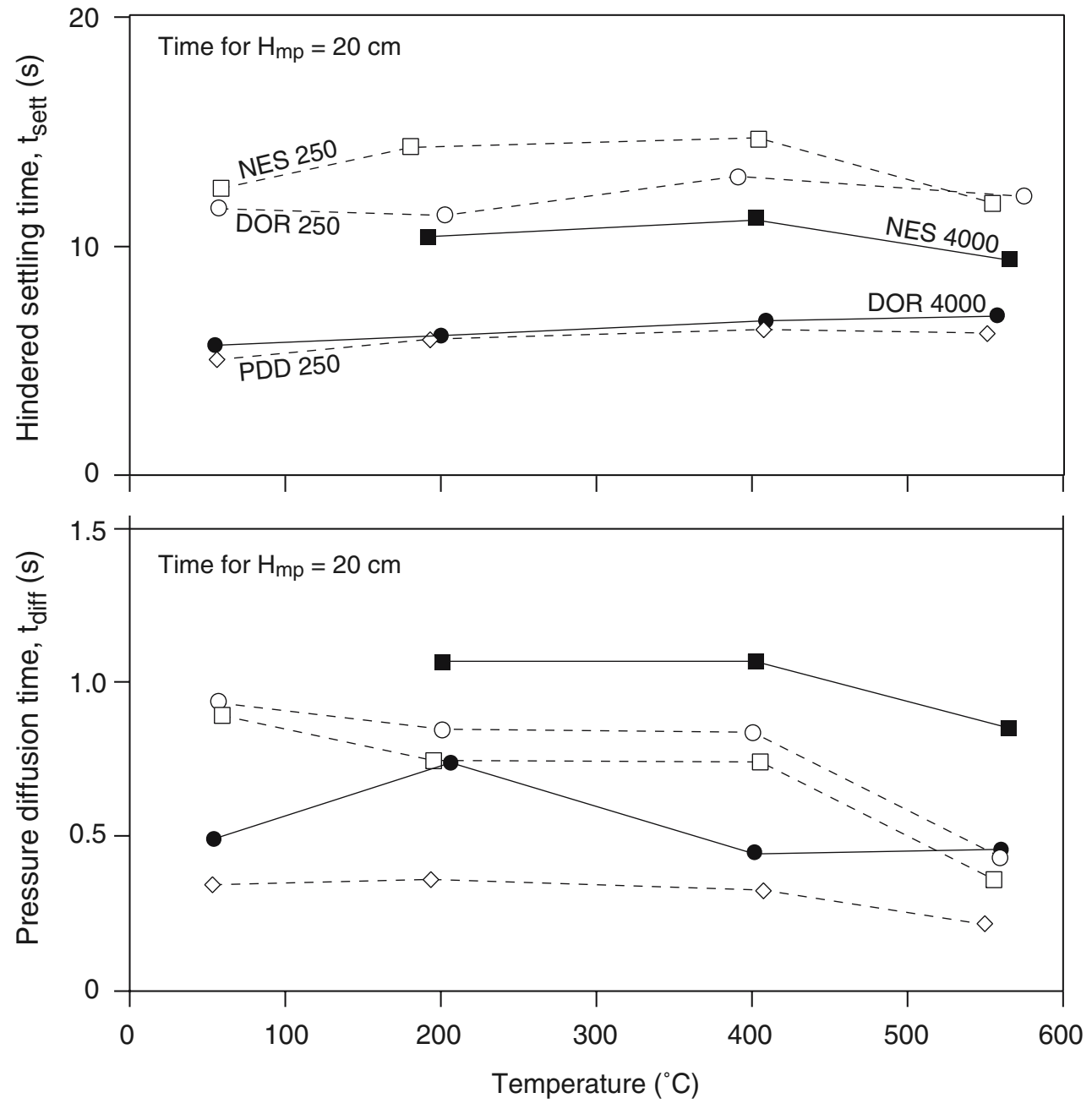

to fall to $7 \%$ of its initial value in thin beds $\left(P_{0} / P_{\mathrm{atm}} \approx 1\right)$ and to $<7 \%$ in thick beds $\left(P_{0} / P_{\text {atm }}>1\right)$.

\section{Calculation of gas retention times}

The experimental results are now used to estimate $t_{\text {sett }}$ and $t_{\text {diff }}$ for our materials. For the collapse tests of experiment set 2,

$t_{\text {sett }}=\frac{\left(H_{\mathrm{be}}-H_{\mathrm{sett}}\right)}{U_{\mathrm{sett}}}$

the results being shown in Fig. 13. Values of $t_{\text {sett }}$ for the sub$250 \mu \mathrm{m}$ samples are up to twice those of their corresponding sub-4 mm samples. Moreover, values for PDD 250 are much lower than those of NES 250 or DOR 250, suggesting that particle density or shape also has an effect. However, there is little thermal dependence evident in these data. At high temperatures the beds expand more, but also settle faster (Fig. 9), and the two effects cancel.

The collapse tests only measure settling time from a single bed expansion height, $H_{\text {be }}$. Data of experiment set
1 , on the other hand, allow us to calculate $t_{\text {sett }}=\left(H-H_{\mathrm{mp}}\right) / U$ as a function of variable expansion by substituting incrementally for $U$ and $H$ (Fig. 14). In all samples the resulting $t_{\text {sett }}$ values rise rapidly with expansion, then either plateau or decrease. Using Eq. 9 we obtain an expression

$t_{\mathrm{sett}} \approx \frac{H_{\mathrm{mp}}\left(H / H_{\mathrm{mp}}-1\right)}{U_{\mathrm{mp}}\left(H / H_{\mathrm{mp}}\right)^{n}}$

that reproduces approximately the form of the data curves (Fig. 14a). As in the collapse data, each sub-250 $\mu \mathrm{m}$ sample yields longer settling times than its corresponding sub-4 mm sample at a given expansion, confirming that particle size has an important influence on $t_{\text {sett }}$ PDD has lower settling times than NES or DOR, possibly due to higher particle densities or more equant particle shapes. However, unlike in the collapse data there is a clear thermal influence on $t_{\text {sett }}$, values for each sub-250 $\mu \mathrm{m}$ sample being higher at $200^{\circ} \mathrm{C}$ than at $55^{\circ} \mathrm{C}$. 

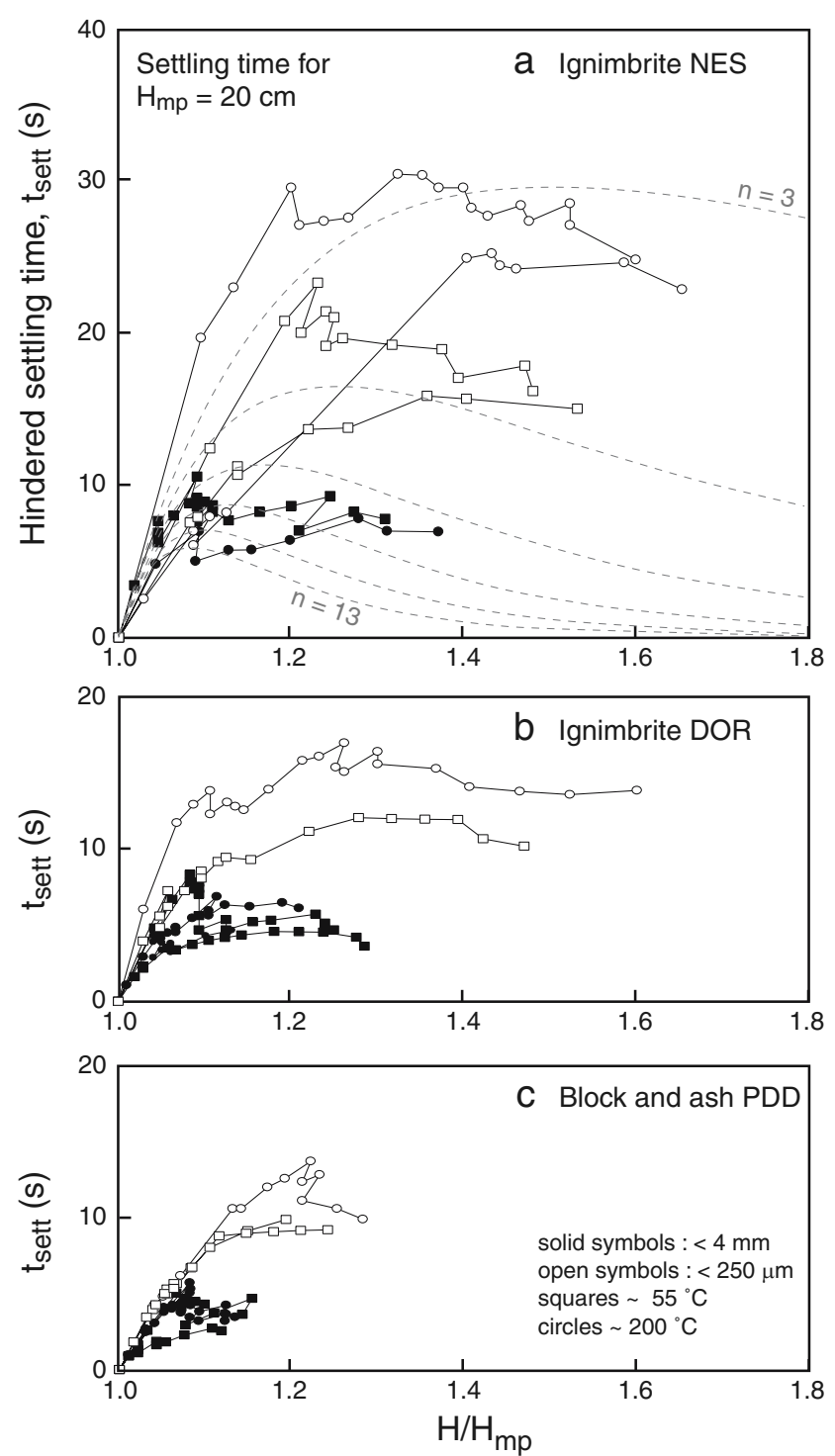

Fig. 14 Hindered settling times as a function of initial bed expansion, calculated from the data of experiment set 1. Each data curve corresponds to the regime of uniform expansion and terminates at the onset of bubbling. The grey dotted curves in (a) are the function given by Eq. 26 for $U_{\mathrm{mp}}=0.1 \mathrm{~cm} \mathrm{~s}^{-1}$. The values are for a nonexpanded bed height of $20 \mathrm{~cm}$

Diffusion times are calculated using the $K_{\mathrm{mp}}$ data of experiment set 2,

$t_{\text {diff }}=\frac{\mu \varepsilon_{\mathrm{mp}} H_{\mathrm{mp}}^{2}}{K_{\mathrm{mp}} P_{\mathrm{atm}}}$

and the values of $\varepsilon$ in Table 1 (Fig. 13). No significant dependence of diffusion time on either temperature or particle size is evident in these data. However, a clear size influence emerges if one takes into account Wilson's (1984) minimum fluidization data for a broader range of particle sizes (Fig. 10), long diffusion time being favoured by finer particle size, which reduces permeability. Sample PDD has the shortest diffusion time in Fig. 13.
Scaling up the gas retention times

The laboratory gas retention times can be scaled up to dimensions more relevant to pyroclastic flows, as shown in Fig. 15. The values of $K$ and $n$ used in the figure span those for our experimental samples, and hence are representative of pyroclastic flow materials with particles up to $4 \mathrm{~mm}$. Times $t_{\text {sett }}$ and $t_{\text {diff }}$ have different dependencies on bed thickness $(H), t_{\text {sett }}$ being proportional to $H$ and $t_{\text {diff }}$ being proportional to $H^{2}$. At small $H$, $t_{\text {sett }}$ is greater than $t_{\text {diff, }}$, so that sediment outgassing is fast relative to settling. This is the case in our laboratory-scale collapse experiments (Fig. 8) and simulation (Fig. 12a). However, the opposite is true at high $\mathrm{H}$, the limit between the two regimes depending on the exact choice of physical parameters, but typically ranging from a few $\mathrm{dm}$ to a couple of m (Fig. 15).

\section{Discussion}

We have carried out experiments in 1-D rigs to determine the gas retention capacities of natural pyroclastic flow materials, and to study their dependences on material properties and temperature. Gas retention capacity is best quantified in terms of the time that a material can retain gas in the absence of any gas regeneration. Laboratory experiments and numerical simulations show that there are three governing timescales. An aerated $\left(U<U_{\mathrm{mp}}\right)$ bed loses its gas by permeable flow on a diffusive timescale $t_{\text {diff. }}$ A bed that is fluidized and uniformly expanded $\left(U_{\mathrm{mp}}<U<U_{\mathrm{mb}}\right)$ on the other hand is governed by two timescales: one related to hindered settling $\left(t_{\text {sett }}\right)$ and the other $\left(t_{\text {diff }}\right)$ related to diffusive outgassing of the resulting sediment layer. In the case of a bubbling bed $\left(U>U_{\mathrm{mb}}\right)$ a third timescale related to bubble evacuation $\left(t_{\mathrm{be}}\right)$ is also relevant; however, bubble evacuation is likely to be very rapid and is probably never the rate-limiting factor. The relative magnitudes of $t_{\text {sett }}$ and $t_{\text {diff }}$ depend on the thickness of the defluidizing bed, $t_{\text {sett }}$ dominating in thin beds and $t_{\text {diff }}$ in thick ones (Fig. 15). These times in turn depend on the fluidization properties of the material.

Effects of material properties and temperature on gas retention

Provided that a careful drying procedure is followed, and the bed is stirred during fluidization, fine-grained pyroclastic flow materials exhibit a regime of uniform expansion prior to the onset of bubbling. Stirring suppresses gas channelling, but also causes premature bubbling in finer samples. Uniform expansion in pyroclastic flow materials is limited to a few tens of percent above the loose-packed state. Large values favour gas retention by decreasing 
Fig. 15 Gas retention times $t_{\text {sett }}$ and $t_{\text {diff }}$ as functions of bed thickness, calculated from Eqs. 26 and 27. $K$ is expressed in units of $\mathrm{m}^{-2}$. Three regimes exist, depending on the relative values of the two times. See text for discussion

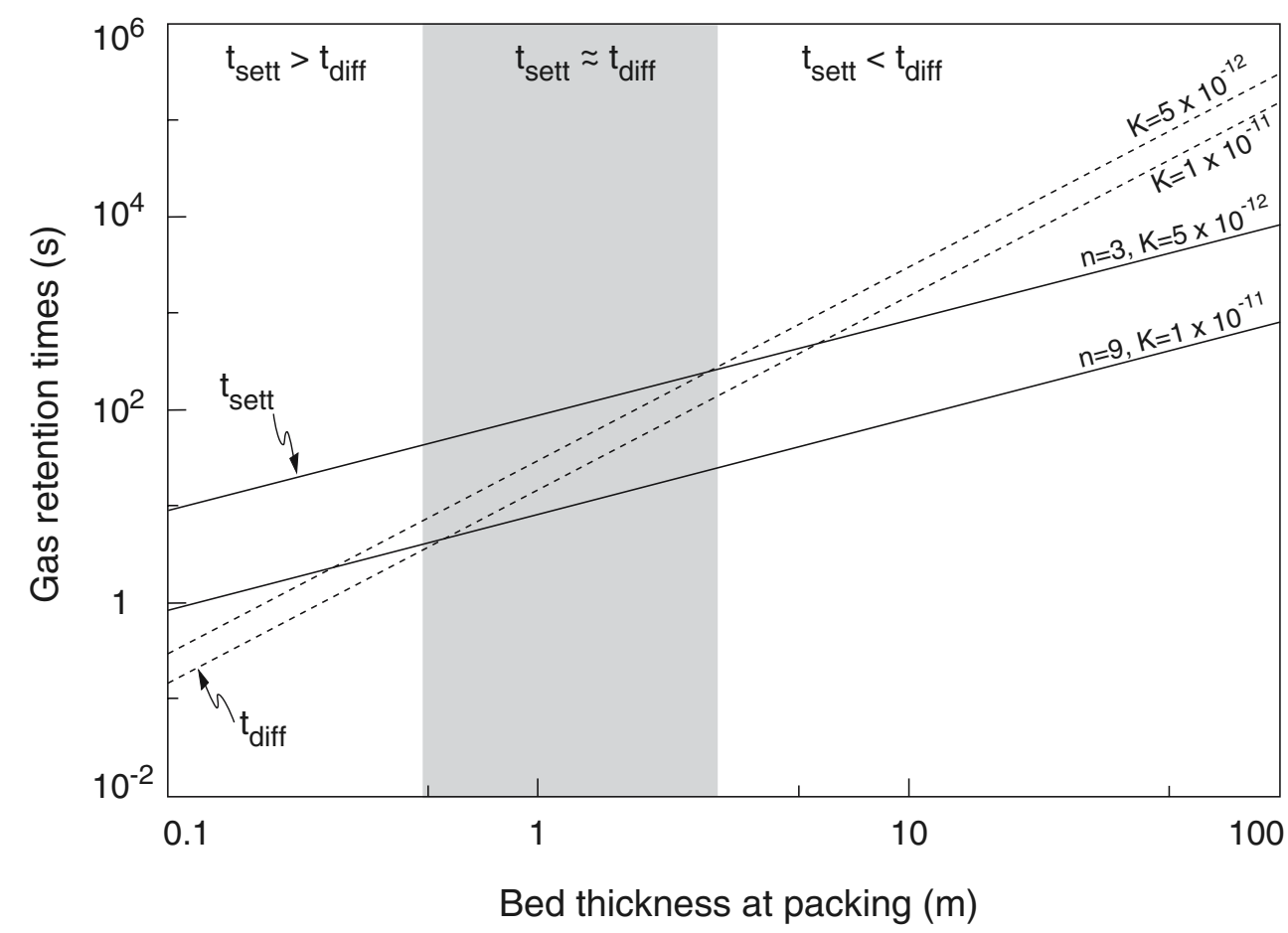

the amount of gas lost by bubbling. Our sub-250 $\mu \mathrm{m}$ samples have higher values of $t_{\text {sett }}$ relative to their corresponding sub-4 mm samples because their fields of uniform expansion, as measured by $H_{\mathrm{mb}} / H_{\mathrm{mp}}$, are broader. The sub-250 $\mu \mathrm{m}$ samples also have smaller values of the Richardson-Zaki exponent, $n$, showing that they expand more readily under vertical gas flow.

The exact influence of particle size is hard to evaluate because the sub-250 $\mu \mathrm{m}$ samples have both smaller mean particle sizes and higher fines contents than their sub-4 mm equivalents. This problem was also encountered by Abrahamsen and Geldart (1980b), who designed experiments to distinguish between the two parameters. These authors observed an important effect of fines content independent of particle mean, and it is now widely accepted that high fines content in particular improves fluidization quality and gas retention in many powders (e.g., Yates and Newton 1986; Lorences et al. 2003; Bruni et al. 2006, 2007). Indeed it is common in industrial applications to add fines in order to increase fluidization quality and hence improve reactor performance (Bruni et al. 2007). We infer that the differences in fines contents between our sub-250 $\mu \mathrm{m}$ and sub-4 mm samples are an important factor in the observed particle size effects. Decreasing fines content by adding coarser particles decreases fluidization quality and gas retention.

This conclusion is consistent with the experimental results of Wilson (1984), who studied the fluidization behaviour of a wide range of pyroclastic flow samples at room temperature. Wilson found that expansion of poorly sorted samples was limited in most cases to less than 10-20\%, whereas the largest values achieved in our study were $\sim 60 \%$ for sub- $250 \mu \mathrm{m}$ ignimbrite ashes. The lower degrees of expansion observed in Wilson's samples are to be expected because (1) they were in general coarser grained than ours, with lower fines contents, and (2) they were generated at lower temperature.

Low particle density also appears to favour uniform fluidization and increase $t_{\text {sett }}$, as tentatively deduced from comparison of block-and-ash sample PDD with ignimbrite samples NES and DOR. Particle shape may also play a role.

High temperatures promote smooth fluidization in our materials by (1) enlarging the regime of uniform expansion, and (2) increasing dense-phase voidage in the bubbling state, as also observed in other powders (Abrahamsen and Geldart 1980b; Rapagna et al. 1994; Xie and Geldart 1995; Yates 1996; Lettieri et al. 2000, 2002). They also favour looser packing and higher permeability in the settled state, possibly due to the thermal growth of cohesive forces. However, the effects of temperature on $t_{\text {sett }}$ and $t_{\text {diff }}$ are both relatively weak. In the case of $t_{\text {sett }}$, this is because greater expansion at higher temperatures is counterbalanced by faster particle settling. In the case of $t_{\text {diff, it is because }}$ higher temperatures result in higher bed permeabilities, but these are counterbalanced by higher gas viscosities.

The lack of major thermal influence on gas retention has important implications for future experimental work using gas-pyroclast mixtures. Provided that humidity-related cohesion is minimized through careful drying, experiments can be carried out at $50-200^{\circ} \mathrm{C}$ and the results extrapolated to higher temperatures. 
Gas retention in pyroclastic flows

The concept of gas retention capacity is commonly applied to the pneumatic transport of powders in industrial pipes, chutes and hoppers. Powders with high retention capacities flow most readily because they are able to maintain excess gas pore pressures and hence reduced friction for long times. For example, the rapid pouring of fine powders into large hoppers generates excess gas pressures that can take many minutes to dissipate (e.g., Murfitt and Bransby 1980, 1982). Materials of low retention capacity, on the other hand, lose excess gas pressure and acquire friction rapidly, causing blockages. The ability of powders to retain gas has consequently been the subject of much research (Abrahamsen and Geldart 1980a, b; Murfitt and Bransby 1980, 1982; Geldart and Wong 1985; Tardos et al. 1985; Lettieri et al. 1999; Bruni et al. 2006, 2007). Very fine cohesive powders (Geldart Group C) retain gas poorly because the gas escapes by channelling. At the other extreme, coarse powders (Groups B and D) lose gas rapidly because they are relatively permeable and prone to bubbling. Powders that flow most readily are those that combine low permeabilities, small cohesions and broad fields of uniform expansion (Group A). This is supported by recent flume experiments on fluidized granular flows using materials belonging to groups A, B and D (Roche et al. 2004)

Excess gas pore pressures and associated fluidization effects are believed to be important in the dynamics of dense pyroclastic flows (Sparks 1976; Wilson 1980), and the concept of gas retention should be equally applicable. A key factor in a pyroclastic flow is the fluidization state of the fine-grained matrix, typically composed of particles less than a $\sim 1 \mathrm{~mm}$ in diameter (Sparks 1976). If the gas velocity is less than $U_{\mathrm{mp}}$ for the matrix, transient particle contacts will persist, the matrix will retain friction, and the pyroclastic flow will travel in the aerated state. If, on the other hand, gas velocity exceeds $U_{\mathrm{mp}}$, the matrix will expand, lose friction, and form a viscous pseudofluid in which larger (nonfluidized) particles are suspended or form a basal traction layer. At least some small pyroclastic flows appear to travel largely in the fluidized regime because they have negligible friction throughout most of their runout (Levine and Kieffer 1991; Druitt et al. 2002).

The ash samples studied in this paper can be thought of as representing the matrices of dense pyroclastic flows. They have properties typical of Group A powders, with negligible cohesion and uniform expansions of up to several tens of percent above loose packing that, by analogy with industrial systems, are favourable for effective pneumatic transport. However, pyroclastic flows have two distinguishing features. Firstly, gas regeneration is likely to be strong in a pyroclastic flow, either by internal (exsolution, pyroclast attrition) or external (burning of vegetation, boiling of surface water) production or by air entrainment as the flow cascades down boulder-strewn drainages or across cliffs (Wilson 1980). Combinations of these sources probably serve to continuously replenish gas as the pyroclastic flow travels across the landscape, and in this context gas retention time can be interpreted in two ways. (1) In order for gas sources to be effective in reducing friction, they must replenish the interstitial gas on a timescale that is shorter than, or comparable to, the retention time. The longer the retention time, the lower the rates of gas regeneration required to maintain low friction. (2) Once the gas sources have become ineffective, it is the retention time that will govern the excess runout duration of the pyroclastic flow. For example, one can envisage a flow in which gas pressure is maintained at a high level by vigorous gas production, but then which decays rapidly once production has declined. Conversely, a high original gas pressure may be maintained for a long time, even if in the absence of further production, provided that the flow retains gas effectively.

A second distinguishing feature of pyroclastic flows is their large scale. Even small pyroclastic flows typically have thicknesses in the range $1-10 \mathrm{~m}$, which is an order of magnitude larger than many industrial powder transport systems $(0.1-1 \mathrm{~m})$. In industry $t_{\text {sett }}$ is commonly the governing timescale for gas retention because diffusive outgassing from the settled state is essentially instantaneous on such scales (Fig. 15). However, this is not true on the scale of a pyroclastic flow, where $t_{\text {sett }}$ and $t_{\text {diff }}$ are either of comparable magnitudes or (at thicknesses greater than a few metres) $t_{\text {diff }}$ is greater than $t_{\text {sett }}$. As an initially expanded pyroclastic flow several metres thick defluidizes it will collapse progressively to form an aerated layer, in a manner analogous to the numerical simulation of Fig. 12b. The aerated material will in turn continue to flow provided that the internal angle of friction is less than the slope of the underlying ground surface. The curves of Fig. 15 imply that $t_{\text {diff }}$ could be an important factor in the runout duration of dense pyroclastic flows thicker than a few metres.

There are several assumptions in applying Fig. 15 quantitatively to pyroclastic flows. One is that shear and mixing effects will prevent gas channelling and promote smooth fluidization in the manner of laboratory stirring. Another is that hindered settling velocities (and hence $t_{\text {sett }}$ values) will be similar to those in 1-D rigs. Both assumptions are justified by recent experiments by Girolami et al. (2006), who fluidized hot ash in a lock-exchange reservoir, then released it down a flume. The resulting flows remained uniformly fluidized as they travelled, without channelling. Moreover, despite high rates of shear, settling rates during flow were similar to those measured in 1-D rigs at the same initial expansion. On the other hand, values of $t_{\text {diff }}$ for aerated pyroclastic flows might be shorter than 1-D 
estimates because permeability might be increased by shear and particle jostling.

Bearing these uncertainties in mind, the curves of Fig. 15 imply that total gas retention times in a pyroclastic flow a few metres thick could range from a few tens to a few hundreds of seconds, depending on the exact physical parameters, the latter being a significant fraction of the emplacement durations of many small flows (typically several minutes). Such flows might therefore maintain low friction for significant lengths of time after gas production or entrainment had ceased to be effective.

\section{Application to Montserrat pyroclastic flows}

Since gas retention is favoured by high fines content, a coarse-grained pyroclastic flow might be expected to lose excess gas pressure more quickly than a finer-grained one, and hence travel further, all other factors being equal. High temperature also favours gas retention, but is of secondary importance. These conclusions are consistent with some recent observations of pyroclastic flow mobility. Calder et al. (1999) showed that pumice flows and surge-derived pyroclastic flows on Montserrat were significantly more mobile than block-and-ash flows of comparable volume, irrespective of the mobility index used and despite lower temperatures $\left(120-410^{\circ} \mathrm{C}\right.$ in the pumice and surge-derived flows; up to $650^{\circ} \mathrm{C}$ in the block-and-ash flows; Cole et al. 2002). They argued that low temperatures ruled out significant internal gas production, and they attributed the high mobility of the pumice and surge-derived flows to (1) rapid settling from pyroclastic suspensions, generating dense gas-pyroclast mixtures with high initial pore pressures, and (2) the fine-grained nature of the constituent materials. The second factor is supported by our data, which show that high fines content could indeed favour longer flow runouts by increasing the gas retention capacities. The relatively low temperatures of the pumice flows and surge-derived flows may not have greatly affected their mobility because gas retention is not very sensitive to temperature.

Acknowledgements We are indebted to John Yates for his enthusiastic support in the early stages of this project and to Olivier Roche for discussions. Colin Wilson and an anonymous reviewer helped improve the manuscript.

\section{Appendix}

\section{Notation}

Symbol

\footnotetext{
A surface area of fluidization rig $\left(\mathrm{m}^{-2}\right)$

$\varepsilon$ hydrodynamic voidage
}

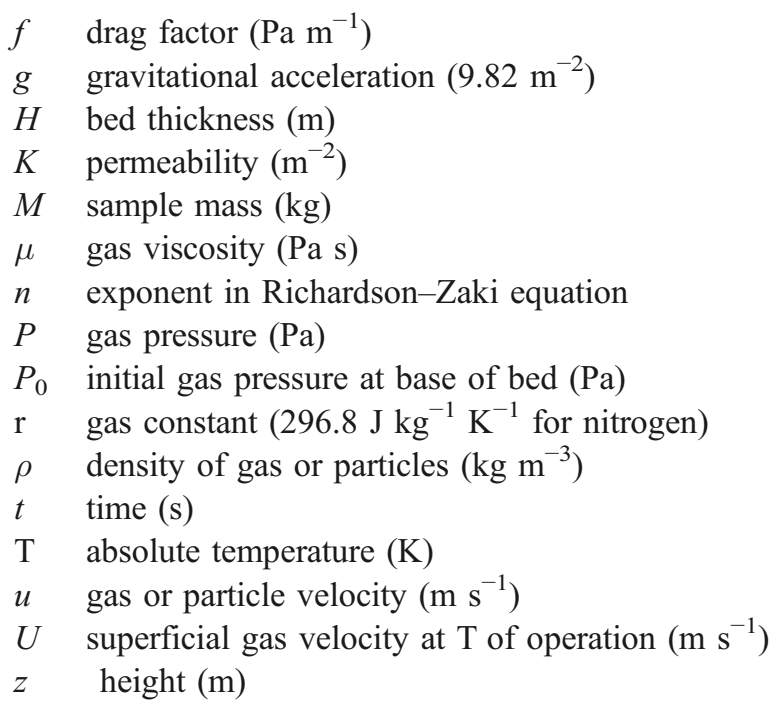

Subscript

atm atmospheric value

be value following bubble evacuation

diff pressure diffusion

g value for gas phase

$\mathrm{mb}$ value at minimum bubbling

$\mathrm{mf}$ value at minimum fluidization

$\mathrm{mp}$ value at maximum pressure

s value for solid phase

sett value during or following settling

$t$ terminal value

\section{References}

Abrahamsen AR, Geldart D (1980a) Behaviour of gas-fluidized beds of fine powders. Part I. Homogeneous expansion. Powder Technol 26:35-46

Abrahamsen AR, Geldart D (1980b) Behaviour of gas-fluidized beds of fine powders. Part II. Voidage of the dense phase in bubbling beds. Powder Technol 26:47-55

Botterill JSM, Teoman Y, Yüregir KR (1982) The effect of operating temperature on the velocity of minimum fluidization, bed voidage and general behaviour. Powder Technol 31:101-110

Boudon G, Camus G, Gourgaud A, Lajoie J (1993) The 1984 nuéeardente deposits of Merapi volcano, Central Java, Indonesia: stratigraphy, textural characteristics, and transport mechanisms. Bull Volcanol 55:327-342

Bruni G, Lettieri P, Newton D, Yates JG (2006) The influence of fines size distribution on the behaviour of gas fluidised beds at high temperature. Powder Technol 163:88-97

Bruni G, Lettieri P, Newton D, Barletta D (2007) An investigation of the effect of the interparticle forces on the fluidization behaviour of fine powders linked with rheological studies. Chem Eng Sci 62:387-396

Calder ES, Cole PD, Dade WB et al (1999) Mobility of pyroclastic flows and surges at the Soufriere Hills Volcano, Montserrat. Geophys Res Lett 26:537-540

Calder ES, Sparks RSJ, Gardeweg MC (2000) Erosion, transport and segregation of pumice and lithic clasts in pyroclastic flows 
inferred from ignimbrite at Lascar Volcano, Chile. J Volcanol Geotherm Res 104:201-235

Cherntongchai P, Brandani S (2005) A model for the interpretation of the bed collapse experiment. Powder Technol 151:37-43

Ciborowski J, Wlodarski A (1962) On electrostatic effects in fluidised beds. Chem Eng Sci 17:23-32

Cole PD, Calder ES, Sparks RSJ, Clarke AB, Druitt TH, Young SR, Herd RA, Harford CL, Norton GE (2002) Deposits from dome-collapse and fountain-collapse pyroclastic flows at Soufrière Hills Volcano, Montserrat. Geol Soc Lond Memoir 21:231-263

Davies DK, Quearry MW, Bonis SB (1978) Glowing avalanches from the 1974 eruption of the volcano Fuego, Guatemala. Geol Soc Am Bull 89:369-384

Druitt TH (1998) Pyroclastic density currents. Geol Society London Spec Publ 145:145-182

Druitt TH, Calder ES, Cole PD, Norton GE, Ritchie LJ, Sparks RSJ, Voight B (2002) Small-volume, highly mobile pyroclastic flows formed by rapid sedimentation from pyroclastic surges at Soufrière Hills Volcano, Montserrat: an important volcanic hazard. Geol Soc Lond Memoir 21:263-281

Druitt TH, Bruni G, Lettieri P, Yates JG (2004) The fluidization behaviour of ignimbrite at high temperature and with mechanical agitation. Geophys Res Lett 31 L02604, DOI 10.1029/ 2003GL018593

Fan L-S, Zhu C (1998) Principles of gas-solid flows. Cambridge University Press, p 557

Folk RL, Ward WC (1957) Brazos River bar, a study in the significance of grain-size parameters. J Sediment Petrol 27:3-26

Formisani B, Girimonte R, Mancuso L (1998) Analysis of the fluidization process of particle beds at high temperature. Chem Eng Sci 53:951-961

Foscolo PU, Gibilaro LG (1984) A fully predictive criterion for the transition between particulate and aggregate fluidization. Chem Eng Sci 39:1667-1675

Freundt A, Bursik M (2001) Pyroclastic flow transport mechanisms. In: Freundt A, Rosi M (eds) From magma to tephra. Elsevier, pp $173-245$

Geldart D (1973) Types of gas fluidization. Powder Technol 7:285292

Geldart D, Wong ACY (1985) Fluidization of powders showing degrees of cohesiveness-II. Experiments on rates of de-aeration. Chem Eng Sci 40:653-661

Girolami L, Druitt TH, Khrabrykh Z, Roche O, Kelfoun K (2006) Propagation of experimental pyroclastic flows. Amer Geophys Union, 87(52), Eos Trans, H53D-0656

Hoblitt RP (1986) Observations of the eruptions of July 22 and August 7, 1980, at Mount St. Helens, Washington. US Geol Surv Prof Paper 1335, p 44

Lettieri P, Newton D, Yates JG (1999) Experimental observations of fluidized beds at high temperatures. Eurasian Chem Technol J 1:9-16

Lettieri P, Yates J, Newton D (2000) The influence of interparticle forces on the fluidization behaviour of some industrial materials at high temperature. Powder Technol 110:117-127

Lettieri P, Newton D, Yates JG (2002) Homogeneous bed expansion of FCC catalysts, influence of temperature on the parameters of the Richardson-Zaki equation. Powder Technol 123:221-231

Levine AH, Kieffer SW (1991) Hydraulics of the August 7, 1980, pyroclastic flow at Mount St. Helens, Washington. Geology 19:1121-1124

Lorences MJ, Patience GS, Diez FV, Coca J (2003) Fines effects on collapsing fluidized beds. Powder Technol 131:234-240
Lucas A, Arnaldos J, Casal J, Puigjaner L (1986) High temperature incipient fluidization in mono and polydisperse systems. Chem Eng Commun 41:121-132

Murfitt PG, Bransby PL (1980) Deaeration of powders in hoppers. Powder Technol 27:149-162

Murfitt PG, Bransby PL (1982) Pressures in hoppers filled with fine powders. Powder Technol 31:153-174

Nezzal A, Large JF, Guigon P (1998) Fluidisation behaviour of very cohesive powders under mechanical agitation. In: Fluidization VIII, Proceedings of the Eighth Engineering Foundation Conference on Fluidization, May 14-19. Amer Inst Chem Eng, pp 77-82

Park JJ, Park JH Chang IS, Kim SD, Choi CS (1991) A new bedcollapsing technique for measuring the dense phase properties of gas-fluidized beds. Powder Technol 66:249-257

Rapagna S, Foscolo PU, Gibilaro LG (1994) The influence of temperature on the quality of gas fluidization. Int $\mathrm{J}$ Multiphase Flow 20:305-313

Raso G, D’Amore M, Formisani B, Lignola PG (1992) The influence of temperature on the properties of the particulate phase at incipient fluidization. Powder Technol 72:71-76

Rhodes M (1998) Introduction to particle technology. Wiley, New York, p 320

Richardson JF, Zaki WN (1954) Sedimentation and fluidization: part I. Trans Inst Chem Eng 32:35-52

Roche O, Gilbertson MA, Phillips JC, Sparks RSJ (2004) Experimental study of gas-fluidized granular flows with implications for pyroclastic flow emplacement. J Geophys Res 109 B10201, DOI 10.1029/2003JB002916

Rowley PD, Macleod NS, Kuntz MA, Karplan AM (1985) Proximal bedded deposits related to pyroclastic flows of May 18, 1980, Mount St. Helens, Washington. Geol Soc Amer Bull 96:1373-1383

Sparks RSJ (1976) Particle size variations in ignimbrites and implications for the transport of pyroclastic flows. Sedimentology 23:147-188

Tardos GI, Mazzone D, Pfeffer R, Degani D, Nir A (1985) Unsteady flow of a compressible gas through consolidated porous media. Application to deaeration of hoppers. Powder Technol 41:135-146

Wallis GB (1969) One dimensional two-phase flow. McGraw-Hill, New York, p 408

Wilson CJN (1980) The role of fluidization in the emplacement of pyroclastic flows: an experimental approach. J Volcanol Geotherm Res 8:231-249

Wilson CJN (1984) The role of fluidization in the emplacement of pyroclastic flows, 2: experimental results and their interpretation. J Volcanol Geotherm Res 20:55-84

Wilson L, Head JW (1981) Morphology and rheology of pyroclastic flows and their deposits, and guidelines for future observations. US Geol Surv Prof Paper 1250:513-524

Xie H-Y, Geldart D (1995) Fluidization of FCC powders in the bubble-free regime: effects of types of gases and temperature. Powder Technol 82:269-277

Yamamoto T, Takarada S, Suto S (1993) Pyroclastic flows from the 1991 eruption of Unzen Volcano, Japan. Bull Volcanol 55:166-175

Yamazaki R, Han NS, Sun ZF, Jimbo G (1995) Effect of chemisorbed water on bed voidage of high temperature fluidised bed. Powder Technol 84:15-22

Yates JG (1996) Effects of temperature and pressure on gas-solid fluidization. Chem Eng Sci 51:167-205

Yates JG, Newton D (1986) Fine particle effects in a fluidized bed reactor. Chem Eng Sci 41:801

Yu AB, Feng CL, Zou RP, Yang RY (2003) On the relationship between porosity and interparticle forces. Powder Technol 130:70-76 